\title{
Obtaining and characterization of PEO layers prepared on CP-Ti in sodium dihydrogen
} phosphate dihydrate acidic electrolyte solution

V. Malinovschi ${ }^{1}$, A. Marin ${ }^{2,7^{*}}$, V. Andrei ${ }^{3}$, E. Coaca ${ }^{2}$, C. N. Mihailescu ${ }^{4}$, Cristian P. Lungu ${ }^{4}$, Cristiana Radulescu ${ }^{5,6}$, Ioana Daniela Dulama ${ }^{5}$

${ }^{1}$ - University of Pitesti, Targul din Vale nr.1, Arges, 110040, Romania

2 - Institute for Nuclear Research Pitesti, str. Campului nr.1, POB 78, Mioveni, Arges,

\section{Romania}

3 - ELSSA Laboratory SRL, str.Crinului nr.26, Pitesti, 110109, Arges, Romania

4 - National Institute for Lasers, Plasma and Radiation Physics, Str. Atomistilor 409, Magurele-Bucharest, 077125, Romania

5 - Valahia University of Targoviste, Institute of Multidisciplinary Research for Science and

Technology, 130004 Targoviste, Romania

${ }^{6}$ - Valahia University of Targoviste, Faculty of Sciences and Arts, 130004 Targoviste,

\section{Romania}

7- Max-Planck-Institut für Plasmaphysik, Boltzmannstr. 2, 85748 Garching, Germany

* Corresponding author at: Institute for Nuclear Research Pitesti, str. Campului nr.1, POB 78, Mioveni, Arges, Romania, tel. 0040742143141, fax. 0040248262449, e-mail marin.alexandru.horia@gmail.com

\begin{abstract}
Phosphorus-incorporated oxide layers were grown on commercially pure titanium during plasma electrolytic oxidation in sodium dihydrogen phosphate dihydrate solution. Microstructure, mechanical and electrochemical behavior of the surface oxides indicated a dominant anatase and rutile structure of $\mathrm{TiO}_{2}$ with nanocrystallites ranging from 45-64 nm and
\end{abstract}


48-98 nm, respectively as well as $\mathrm{Ti}^{2+}, \mathrm{Ti}^{3+}$ and $\mathrm{Ti}^{4+}$ chemical species. Using a combination of process time, applied current and electrolyte concentration, coating thicknesses up to about 10 $\mu \mathrm{m}$ were fabricated. Best mechanical performance was observed for potentiostatic deposited samples yielding a $453 \mathrm{HV}_{300}$ hardness, $19 \mathrm{~N}$ adhesive failure and $38 \mathrm{~N}$ full delamination resistance. All PEO-coated samples in this work exhibit a corrosion current density with one order of magnitude lower than CP-Ti when subjected to Ringer's physiological solution.

Keywords: plasma electrolytic oxidation, CP-Ti, titanium dioxide layer, hardness/adhesion, corrosion resistance, microstructure, incorporation of $\mathrm{P}$

\section{Introduction}

Much has been written about titanium and its alloys due to their widespread use in various areas including clinical applications, aerospace, marine, petrochemical, etc. [1, 2]. By possessing favorable properties such as compatibility with the biological environment, good mechanical behavior and corrosion resistance, commercially pure titanium (CP-Ti) was particularly distinguished in medical and surgical usage [3]. In this regard, special attention was devoted to the study of CP-Ti material from mechanical, microstructure, wear and corrosion point of view [4-6]. Additionally, recent developments in the field of titanium alloys were tailored for biomedical and industrial applications using surface modification-treatments, such as selective laser melting [4], pulsed electron beam [7], chemical etching [8], plasma spraying [9]. A recent suitable approach to enhance the surface properties of a pure light metal $(\mathrm{Mg}, \mathrm{Al}, \mathrm{Ti}, \mathrm{Zr}$ ) or its alloyed form by growing corrosion and wear resistant and high-hardness ceramic-like coatings is through plasma electrolytic oxidation (PEO) technique [32]. The PEO process attracted attention due to its ability to form scratch-resistant films with controlled morphology and composition [10]. On one hand, the porous oxide coating promotes cell 
attachment and bone tissue formation [10] as well as mechanical engineering applications [2], plasma electrolytic oxidized $\mathrm{Ti}$ alloy being appropriate for biological and industrial environments. Moreover, research efforts have been made to achieve porous-coated Ti by means of chemical treatment including acid, alkali and $\mathrm{H}_{2} \mathrm{O}_{2}$ in order to improve biocompatibility and bioactivity of titanium biomaterials $[1,8]$. On the other hand, rutile, one of the three crystalline forms of titania $\left(\mathrm{TiO}_{2}\right)$ has been studied in the literature due to its beneficial corrosion resistance. Shokouhfar et al. [11] showed that oxide layers exhibiting increased rutile content were associated with increased corrosion resistance in contrast to anatase phase. It is worth mentioning that the electrochemical response was investigated in Ringer's physiological solution and the best anticorrosion performance was obtained for the oxide coating prepared in phosphate electrolyte. Furthermore, a similar observation was reported by Kumar et al. [12] when using thermal oxidized CP-Ti in Ringer's physiological solution.

Additionally, Xia and Jing paid particular attention to the role of phosphorus in constraining anatase-rutile transition process for photocatalytic activity of $\mathrm{TiO}_{2}[13,14]$. Although further literature studies indicate phosphorus as an inhibitor of anatase-rutile phase transformation by stabilizing the anatase phase $[13,15]$, the present study shows the development of anataserutile mixture phases with the increasing rutile content during film deposition.

Nevertheless, controlled phase transformation of $\mathrm{TiO}_{2}$ using $\mathrm{PEO}$ processing technique has not been reported in the literature. However, very few studies were conducted using plasma electrolysis method on CP-Ti and sodium phosphate electrolyte as oxidizing environment, with and without corrosion resistance testing and with no particular reference to anatase to rutile phase transition [10, 16-18].

Summarizing, the aim of the present paper is preparation and characterization of the protective oxide coatings developed for biomedical and industrial applications on commercially pure 
titanium through electrochemical deposition process using sodium dihydrogen phosphate dihydrate aqueous solution $\left(\mathrm{NaH}_{2} \mathrm{PO}_{4} \cdot 2 \mathrm{H}_{2} \mathrm{O}\right)$. Both phosphorus and calcium are fundamental for bone growth and development [1] enhancing mechanical properties and biocompatibility [3] and hence, simulated body fluids were employed for carrying out the corrosion resistance tests of the coated CP-Ti samples. We suggest that the first step towards calcium phosphate formation is the preferential adsorption of phosphate ions into the coating layers [19], which was proved in our present study. Thus, according to literature data, hydroxyapatite and tricalcium phosphate possess the highest biological activity and osseointegration capacity [20]. In this paper, we investigate the effects of acidic electrolyte solution containing $\mathrm{NaH}_{2} \mathrm{PO}_{4} \cdot 2 \mathrm{H}_{2} \mathrm{O}$ and of electric current density on phosphorus incorporation, microstructure, mechanical properties and corrosion resistance in Ringer's physiological solution of the PEO layers deposited on pure Ti. The novelty of our approach is to enhance rutile phase formation and to increase the rutile/anatase fraction present in the surface layers by tailoring the deposition parameters inside the electrolytic tank during film growth, both potentiostatically and galvanostatically under various sodium phosphate concentrations and treatment times. Further research work will include the effect of calcium and phosphorus based electrolytes under different $\mathrm{PEO}$ processing conditions on $\mathrm{CP}-\mathrm{Ti}$ for controlled $\mathrm{TiO}_{2}$ phase transformation and its corrosion resistance enhancement as well as in vitro bone-like tissue formation on prepared Ti coatings.

\section{Experimental}

\subsection{Preparation of PEO coatings}

Plasma electrolytic oxidation of CP-Ti grade 2 samples was performed using a unipolar pulsed DC power source with $150 \mathrm{~Hz}$ frequency [21]. 
Aqueous solutions of sodium dihydrogen phosphate dihydrate $\left(\mathrm{NaH}_{2} \mathrm{PO}_{4} \cdot 2 \mathrm{H}_{2} \mathrm{O}\right)$ at concentrations of $10 \mathrm{~g} / \mathrm{L}, 20 \mathrm{~g} / \mathrm{L}$ and $30 \mathrm{~g} / \mathrm{L}$ were prepared from chemically pure reagents and distilled water. $\mathrm{pH}$ and electrical conductivity measurements for the obtained electrolytes yielded values of 5.0, 4.6, 4.4 and $6.0,11.9,15.8 \mathrm{mS} / \mathrm{cm}$, respectively.

Prior to the PEO treatment, the CP-Ti grade 2 sheets were cut to rectangular shapes of $1.4 \mathrm{~cm} \times 2.0 \mathrm{~cm}$ and used as substrate metal, followed by mechanical grinding using silicon carbide sand paper of 240, 320 and 1200 grit. The samples were further ultrasonicated in acetone and double-distilled water for 10 minutes before oxidation process.

Three sets of samples were subjected to plasma electrolytic oxidation treatment.

Samples from the first set (S1) were potentiostatically treated at $200 \mathrm{~V}$ for 10,20 and 30 min in a $20 \mathrm{~g} / \mathrm{L} \mathrm{NaH} \mathrm{PO}_{4} \cdot 2 \mathrm{H}_{2} \mathrm{O}$ electrolyte solution. By slowly increasing the actual value of the voltage, spark discharges $\left(\mathrm{U}_{\mathrm{sp}}=120 \mathrm{~V}\right)$ took place, the voltage being further increased to $200 \mathrm{~V}$ and maintained at this value for the designated treatment period. The electrolyte temperature was kept at $20^{\circ} \mathrm{C}$.

In the second set of samples (S2), the oxidation process was carried out through a 20 $\mathrm{g} / \mathrm{L} \mathrm{NaH} \mathrm{PO}_{4} \cdot 2 \mathrm{H}_{2} \mathrm{O}$ aqueous electrolyte for 10 min under a galvanostatic regime at current densities of $0.18 \mathrm{~A} / \mathrm{cm}^{2}, 0.36 \mathrm{~A} / \mathrm{cm}^{2}$ and $0.54 \mathrm{~A} / \mathrm{cm}^{2}$. The actual value of the voltage has been increased such that the current intensity does not exceed 1 A, 2 A and 3 A (effective values), respectively, until spark discharges occur. At this moment, the current intensity was rapidly increased to one of the above mentioned values and maintained throughout the oxidation process. An electrolyte temperature of $22{ }^{\circ} \mathrm{C}$ was held during the experiment.

For the third set of samples (S3), the electrochemical oxidation process was performed for 10 min using a galvanostatic regime, applying a current density of $0.18 \mathrm{~A} / \mathrm{cm}^{2}$ in a $\mathrm{NaH}_{2} \mathrm{PO}_{4} \cdot 2 \mathrm{H}_{2} \mathrm{O}$ aqueous electrolyte solution at concentrations of $10 \mathrm{~g} / \mathrm{L}, 20 \mathrm{~g} / \mathrm{L}$ and $30 \mathrm{~g} / \mathrm{L}$. 
The electrolyte temperature did not exceed $15{ }^{\circ} \mathrm{C}$ during the treatment process. Table 1 summarizes the above oxidation parameters together with the values of impulse amplitudes.

Table 1

Sample codes and preparation conditions for the three sets of experiments.

\begin{tabular}{cccc}
\hline $\begin{array}{c}\text { Sample code/ } \\
\text { set }\end{array}$ & PEO regime & $\begin{array}{c}\text { Electrolyte } \\
\text { concentration/ } \\
\text { PEO process duration }\end{array}$ & I(A) or U(V); $\eta$ \\
\hline Ti1_10M/S1 & Potentiostatic: $200 \mathrm{~V}$ & $20 \mathrm{~g} / \mathrm{L} / 10 \mathrm{~min}$. & $1-1.2 ; 30 \%$ \\
Ti2_20M/S1 & Potentiostatic: $200 \mathrm{~V}$ & $20 \mathrm{~g} / \mathrm{L} / 20 \mathrm{~min}$. & $1-2.2 ; 30 \%$ \\
Ti3_30M/S1 & Potentiostatic: $200 \mathrm{~V}$ & $20 \mathrm{~g} / \mathrm{L} / 30 \mathrm{~min}$. & $1-3.0 ; 30 \%$ \\
Ti1A_10M/S2 & Galvanostatic: $0.18 \mathrm{~A} / \mathrm{cm}^{2}$ & $20 \mathrm{~g} / \mathrm{L} / 10 \mathrm{~min}$. & $200-170 ; 30 \%$ \\
Ti2A_10M/S2 & Galvanostatic: $0.36 \mathrm{~A} / \mathrm{cm}^{2}$ & $20 \mathrm{~g} / \mathrm{L} / 10 \mathrm{~min}$. & $220-190 ; 33 \%$ \\
Ti3A_10M/S2 & Galvanostatic: $0.54 \mathrm{~A} / \mathrm{cm}^{2}$ & $20 \mathrm{~g} / \mathrm{L} / 10 \mathrm{~min}$. & $270-210 ; 37 \%$ \\
Ti1A_10g/S3 & Galvanostatic: $0.18 \mathrm{~A} / \mathrm{cm}^{2}$ & $10 \mathrm{~g} / \mathrm{L} / 10 \mathrm{~min}$. & $160-240 ; 33 \%$ \\
Ti1A_20g/S3 & Galvanostatic: $0.18 \mathrm{~A} / \mathrm{cm}^{2}$ & $20 \mathrm{~g} / \mathrm{L} / 10 \mathrm{~min}$. & $110-180 ; 30 \%$ \\
Ti1A_30g/S3 & Galvanostatic: $0.18 \mathrm{~A} / \mathrm{cm}^{2}$ & $30 \mathrm{~g} / \mathrm{L} / 10 \mathrm{~min}$. & $100-140 ; 27 \%$ \\
\hline
\end{tabular}

*I, U - actual values; $\eta$ - duty cycle

\subsection{Characterization of PEO coatings}

XPS measurements were performed with an Escalab 250Xi system (Thermo Scientific) equipped with a monochromated $\mathrm{Al} \mathrm{K \alpha}(1486.6 \mathrm{eV}) \mathrm{X}$-ray source and a base pressure in the analysis chamber of $10^{-8} \mathrm{~Pa}$. The acquired spectra were calibrated with respect to the $\mathrm{C} 1 \mathrm{~s}$ line of surface adventitious carbon at $284.8 \mathrm{eV}$. An electron flood gun has been used to compensate the charging effect in insulating samples.

The XRD analysis was carried out using a Rigaku Ultima IV diffractometer equipped with a D/teX Ultra high-speed one-dimensional detector. $\mathrm{Cu} \mathrm{K}_{\alpha 1, \alpha 2}$ radiation $(1.5418 \AA$ А, $40 \mathrm{KV}$, $30 \mathrm{~mA})$, a standard support, Bragg-Brentano $(\theta-\theta)$ focusing scheme and a graphite monochromator in diffracted beam were employed. Slit conditions are the following: $\mathrm{DS}=2 / 3^{\circ}$, SS-open, RS-open, DHL $=10 \mathrm{~mm}$ and soller slit $5^{\circ}$ in the incident and in the diffracted beam.

Samples were scanned under a diffraction angle $(2 \theta)=20-80^{\circ}$, with a step width of $0.05^{\circ}$ and a scan speed of $2 \%$ min for the qualitative phase analysis. 
$\mathrm{TiO}_{2}$ rutile and anatase relative concentrations were estimated through Spurr-Myers equation [22] by collecting A (101) and R (110) diffraction lines, as follows: scan range $(2 \theta)=24-28.5^{\circ}$, at a step width of $0.025^{\circ}$ and a scan speed of $0.5^{\circ} / \mathrm{min}$. The crystallite sizes were evaluated from modified Scherrer formula $[23,36]$ by determining the broadening of the A (101) and R (110) characteristic peaks of the $\mathrm{TiO}_{2}$ anatase and rutile phase, respectively. For an accurate microstructural analysis, instrumental broadening was taken into account by measuring the (110) reflection of $\mathrm{LaB}_{6}(\mathrm{SRM} 660 \mathrm{~b})$ standard powder acquired in the angular range of 29.5$31.5^{\circ}$, in the above-mentioned experimental conditions.

SEM/EDS investigations were carried out using a HITACHI SU-70 field emission scanning electron microscope (FESEM) equipped with UltraDry energy-dispersive X-ray analyzer (EDS) and MagnaRay wavelength-dispersive spectrometer (WDS), with an operating voltage of $0.1-30 \mathrm{kV}$, magnification range between $30-800000 \mathrm{X}$ and $1 \mathrm{~nm}$ resolution at $15 \mathrm{kV}$ acceleration voltage.

An Olympus GX71 metallographic microscope was employed to observe the layered structure of the PEO coatings. The samples were prepared by cutting strips using a diamond saw (Isomet4000) and embedding them in thermosetting resin with the METAPRESS-A (Metkon) mounting press. The mechanical cleaning process including grinding and polishing was performed with abrasive papers of 1200 and 2400-4000 grits, respectively.

Adhesion strength of the coatings to the substrate was performed using a Teer ST-30 scratch tester equipped with a $0.2 \mathrm{~mm}$ radius diamond tip. The applied load was ranging from 0 to $100 \mathrm{~N}$ across the coated surface with a scratch speed of $10 \mathrm{~mm} / \mathrm{min}$.

The hardness of the coating layers was measured with a Vickers microhardness tester (AHOTEC $700 \mathrm{FM}$ ) under an applied load of $1000 \mathrm{gf}$ and a dwell time of $15 \mathrm{~s}$, using a diamond Knup indenter, the average microhardness being tabulated and reported. 
The electrochemical measurements were accomplished with a PARSTAT-2273 potentiostat/galvanostat (Advanced Electrochemical System, Princeton Applied Research) in the voltage range of -0.3 to $+1.0 \mathrm{~V}$ with a scan rate of $1.0 \mathrm{mV} / \mathrm{s}$ in a Ringer's physiological solution as a corrosive environment $\left(8.6 \mathrm{~g} / \mathrm{L} \mathrm{NaCl}, 0.3 \mathrm{~g} / \mathrm{L} \mathrm{KCl}\right.$ and $\left.0.33 \mathrm{~g} / \mathrm{L} \mathrm{CaCl} 2 \cdot 2 \mathrm{H}_{2} \mathrm{O}\right)$ at room temperature, using a conventional three-electrode electrochemical cell configuration.

\section{Results and discussions}

\subsection{XPS analysis}

X-ray photoelectron spectroscopy was employed to probe the surface chemistry of the PEO coatings and to confirm the oxide layer formation as a result of the chemical interaction between the phosphate-based electrolyte and the metal substrate. The XPS results were divided into three groups corresponding to the experimental preparation conditions (Table 1). Therefore, Figs. 1-3 show the experimental observations of the PEO-treated Ti surface with respect to the three particular treatment conditions, such as: potentiostatic and galvanostatic operation modes and concentration gradient effect, respectively. A general overview of the results reveals a similar chemical behavior during oxidation process, the attached chemical species on the coated $\mathrm{Ti}$ surface differing only quantitatively as a function of deposition parameters (Figs. 1-3, Table 3). The assessment of the surface chemistry was done based on the XPS transitions of interest, confirming the existence of Ti oxidation states. Thus, Ti2p corelevel spectra were fitted with three components located at $455.5 \mathrm{eV}, 457.2 \mathrm{eV}$ and $458.7 \mathrm{eV}$ corresponding to $\mathrm{Ti}^{2+}, \mathrm{Ti}^{3+}$ and $\mathrm{Ti}^{4+}$ species, respectively, being in excellent agreement with literature data $[24,25]$. The deconvolution of P2p photoemission spectra showed the presence of phosphates and phosphites and consisted of four contributions at $128.1 \mathrm{eV}, 129.6 \mathrm{eV}, 131.7$ $\mathrm{eV}$ and $133.2 \mathrm{eV}$, which were ascribed to metal phosphides [24, 25], elemental phosphorus [24], P-C bonds [26] and phosphate [25] respectively, well consistent with previous reports. 
The oxygen chemistry was evaluated by deconvoluting the O1s level into three features located at $530.2 \mathrm{eV}, 531.5 \mathrm{eV}$ and $532.7 \mathrm{eV}$ and attributed to $\mathrm{O}^{2-}, \mathrm{OH}$ groups and $\mathrm{H}_{2} \mathrm{O}$, respectively [27]. Quantitative data analysis presented in Table 2 shows a rather constant amount of phosphorus $(\sim 10 \%)$ available on the surface. Additionally, significantly differentiated results were found in the case of the first sample set after 20 min plasma oxidation, indicating the lowest amount of $\mathrm{Ti}^{2+}$ accompanied by the highest $\mathrm{Ti}^{4+}$ content (Table 3). The $\mathrm{Ti}^{3+}$ concentration has a constant contribution value, independent of the chosen experimental conditions and of the other two Ti oxidation states, respectively (Table 3). Moreover, the above-mentioned tendencies are in agreement with phosphorus chemistry since phosphides and phosphates have the lowest and the highest values, respectively (Table 3). One possible explanation for these findings could be the enhancement of $\mathrm{OH}$ concentration detected following the 20 min treatment time (Table 3). From thermodynamic point of view, D.-J. Won et al. [28] explains the constant value of $\mathrm{Ti}^{3+}$ and its formation and accumulation on the surface at elevated temperatures using the comparison of standard heats of formation for titanium oxides.

On the other hand, the theoretical approach of $\mathrm{Ti}^{4+}$ and $\left(\mathrm{PO}_{4}\right)^{3-}$ ions formation provides the following mechanism to accomplish this [19]:

$$
\begin{aligned}
& \mathrm{Ti}(\mathrm{OH})_{(\mathrm{ox})}{ }^{3+}+\mathrm{H}_{2} \mathrm{PO}_{4}{ }^{-}{ }_{(\mathrm{aq})} \leftrightarrow \mathrm{Ti}_{(\mathrm{ox})}{ }^{4+} \cdot \mathrm{HPO}_{4}{ }^{2-}{ }_{(\mathrm{ads})}+\mathrm{H}_{2} \mathrm{O} \\
& \mathrm{Ti}_{(\mathrm{ox})}{ }^{4+} \cdot \mathrm{HPO}_{4}{ }^{2-}{ }_{(\mathrm{ads})}+\mathrm{OH}^{-} \leftrightarrow \mathrm{Ti}_{(\mathrm{ox})}{ }^{4+} \cdot \mathrm{PO}_{4}{ }^{3-}{ }_{(\mathrm{ads})}+\mathrm{H}_{2} \mathrm{O}
\end{aligned}
$$

where (ads), (ox) and (aq) represent adsorbed ions and ions in oxide and aqueous solution, respectively.

Therefore, it can be seen that theoretical and experimental results are in close agreement showing adsorption and incorporation of phosphate ions to the titanium surface and also indicating that all PEO-treated samples consist of fully oxidized titanium layers. Moreover, the oxide formed on the surface has a passivating effect on pure $\mathrm{Ti}$, creating an interface between 
the biological environment and the artificial material and hence, the biocompatibility of titanium is closely related with its surface oxides [29].
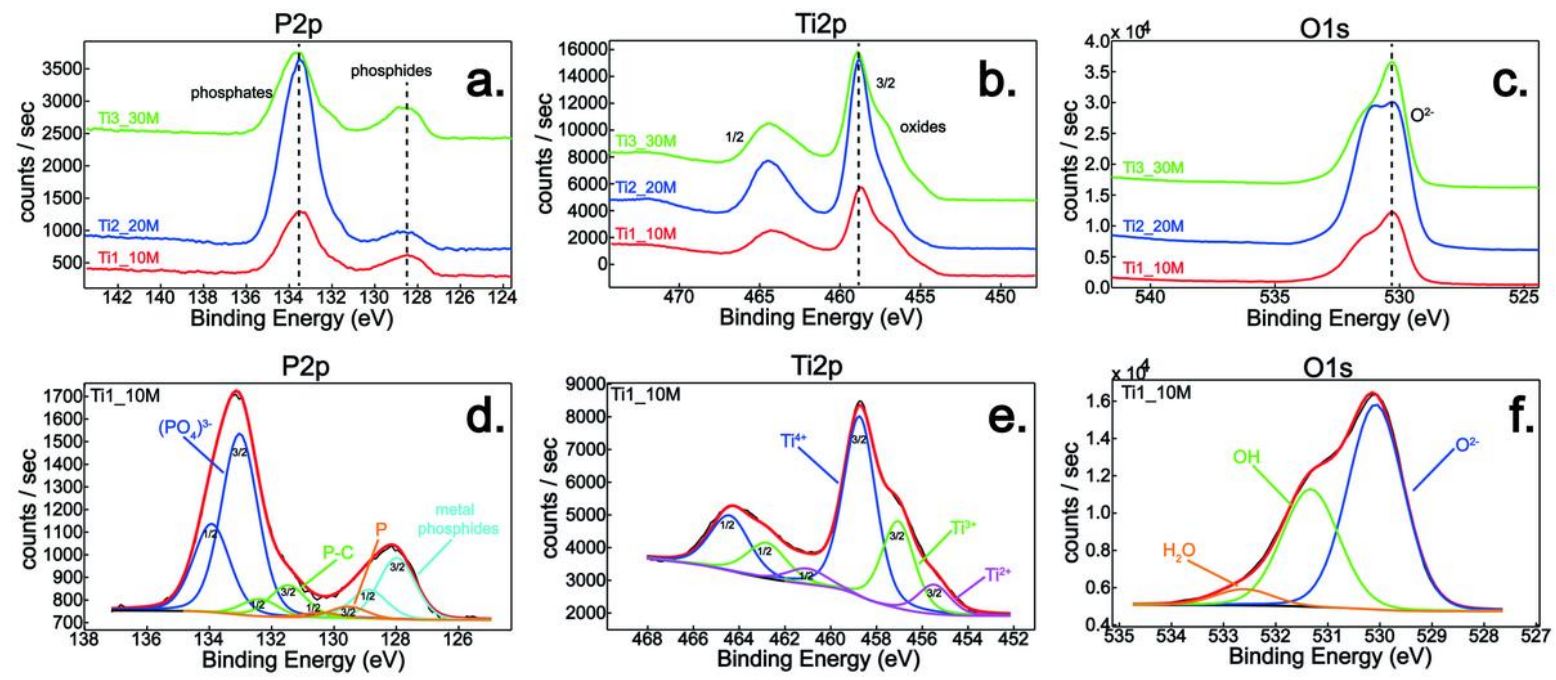

Fig. 1. The XPS superimposed spectra for the first set of samples: a) P2p; b) Ti2p; c) O1s. The XPS deconvoluted high-resolution spectra for the first set of samples prepared after 10 min treatment time:

d) P2p; e) Ti2p; f) O1s.
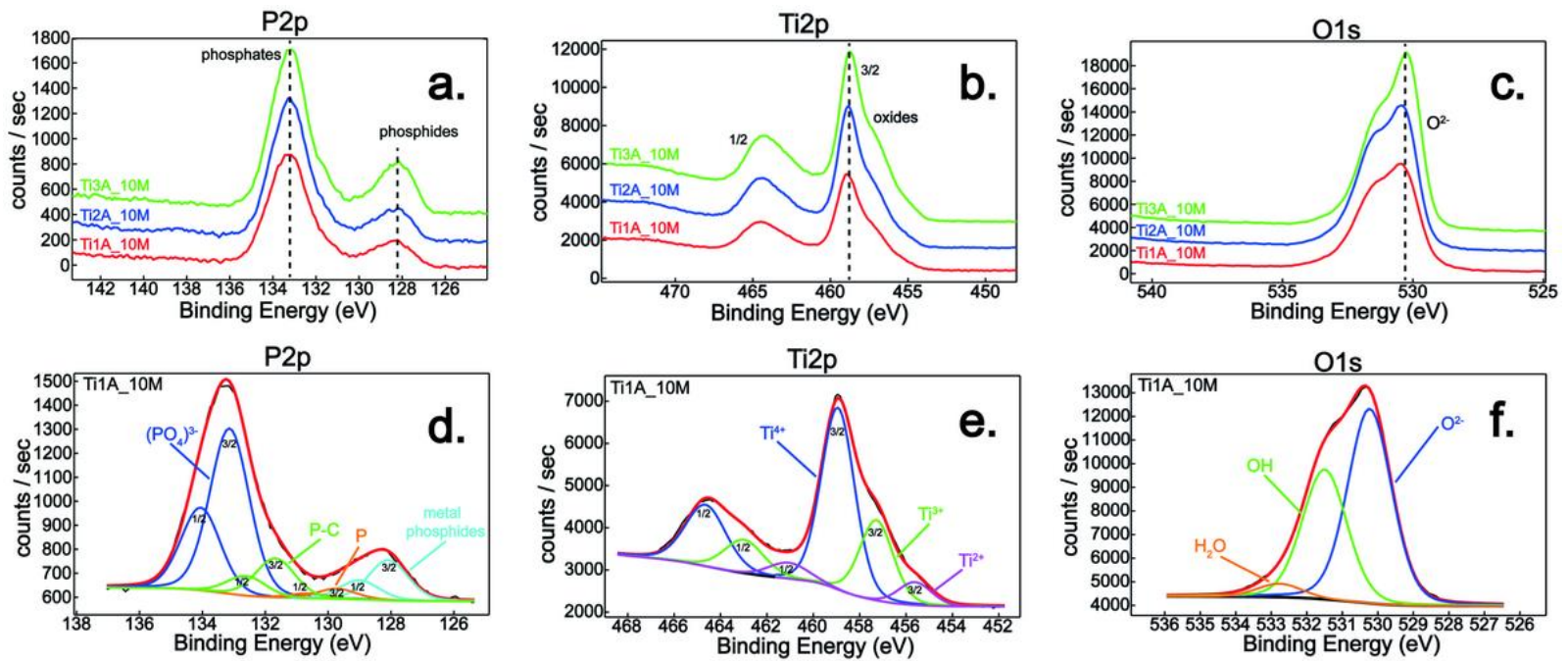

Fig. 2. The XPS superimposed spectra for the second set of samples: a) P2p; b) Ti2p; c) O1s. The

XPS deconvoluted high-resolution spectra for the second set of samples prepared after $10 \mathrm{~min}$ and 1

A treatment conditions: d) P2p; e) Ti2p; f) O1s. 

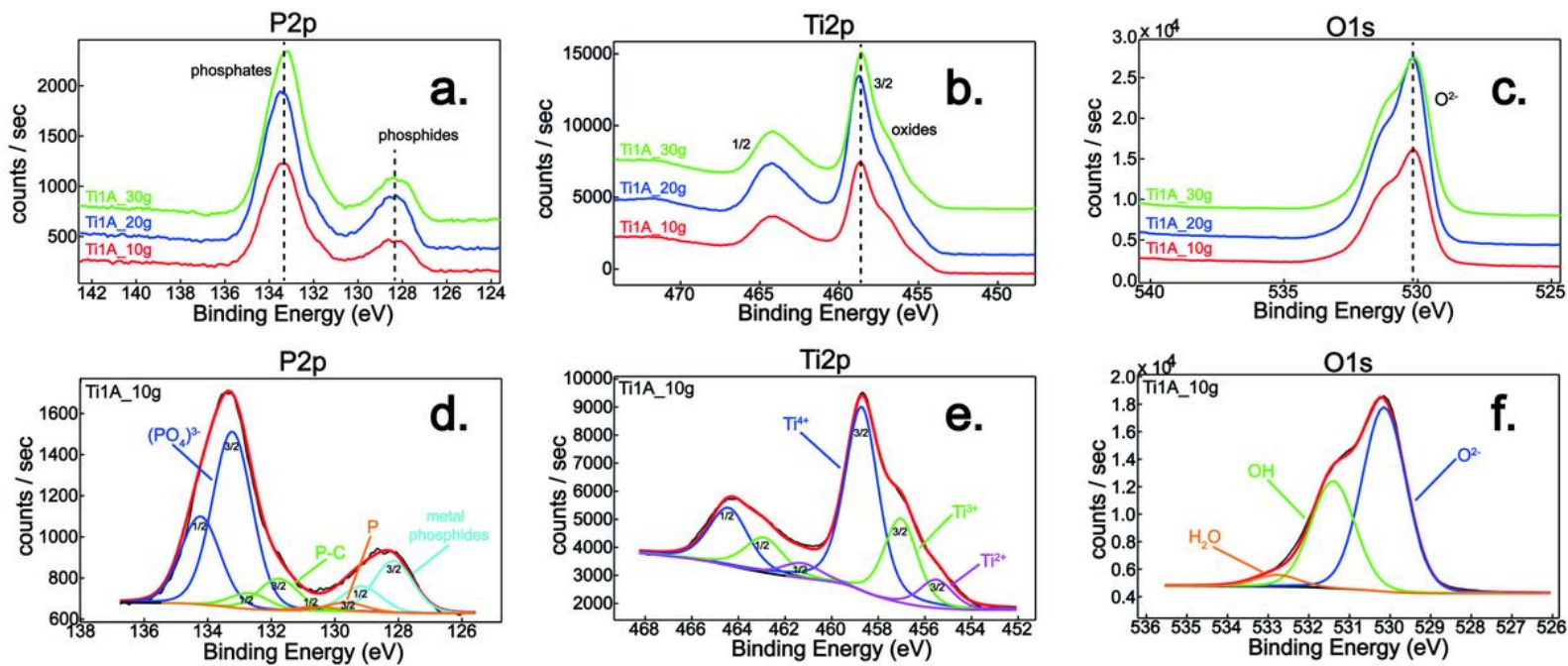

Fig. 3. The XPS superimposed spectra for the third set of samples: a) P2p; b) Ti2p; c) O1s. The XPS deconvoluted high-resolution spectra for the third set of samples prepared in $10 \mathrm{~g} / \mathrm{L} \mathrm{NaH} \mathrm{NO}_{4} \cdot 2 \mathrm{H}_{2} \mathrm{O}$ electrolyte solution: d) P2p; e) Ti2p; f) O1s.

Table 2

Element relative concentrations (at. \%).

\begin{tabular}{ccccc}
\hline Sample code & O1s & Na1s & P2p & Ti2p \\
\hline Ti1_10M & 65.7 & 1.3 & 10.1 & 22.9 \\
Ti2_20M & 67.9 & 2.7 & 10.8 & 18.6 \\
Ti3_30M & 65.7 & 1.2 & 8.8 & 24.3 \\
Ti1A_10M & 69.0 & 1.7 & 10.4 & 18.9 \\
Ti2A_10M & 68.3 & 0.9 & 9.8 & 21.0 \\
Ti3A_10M & 65.5 & 1.7 & 10.2 & 22.6 \\
Ti1A_10g & 67.2 & 1.1 & 9.2 & 22.5 \\
Ti1A_20g & 66.0 & 1.7 & 8.8 & 23.5 \\
Ti1A_30g & 66.6 & 2.2 & 10.0 & 21.2 \\
\hline
\end{tabular}

Table 3

Phosphorus, titanium and oxygen chemistry: Surface chemical species and chemical states relative concentrations.

\begin{tabular}{ccccccc}
\hline $\begin{array}{c}\text { Sample } \\
\text { code }\end{array}$ & $\begin{array}{c}\text { Phosphorus } \\
\text { chemical } \\
\text { species }\end{array}$ & $\begin{array}{c}\text { Phosphorus } \\
\text { chemical } \\
\text { states relative } \\
\text { concentrations } \\
(\%)\end{array}$ & $\begin{array}{c}\text { Titanium } \\
\text { chemical } \\
\text { species }\end{array}$ & $\begin{array}{c}\text { Titanium } \\
\text { chemical } \\
\text { states relative } \\
\text { concentrations } \\
(\%)\end{array}$ & $\begin{array}{c}\text { Oxygen } \\
\text { chemical } \\
\text { species }\end{array}$ & $\begin{array}{c}\text { Oxygen } \\
\text { chemical } \\
\text { states relative } \\
\text { concentrations } \\
(\%)\end{array}$ \\
\hline Ti1_10M & TiP & 21.0 & $\mathrm{Ti}^{2+}$ & 11.4 & $\mathrm{O}^{2-}$ & 61.6 \\
& $\mathrm{P}$ & 3.9 & $\mathrm{Ti}^{3+}$ & 30.8 & $\mathrm{OH}$ & 33.9
\end{tabular}




\begin{tabular}{|c|c|c|c|c|c|c|}
\hline & $\begin{array}{c}\mathrm{P}-\mathrm{C} \\
\left(\mathrm{PO}_{4}\right)^{3-}\end{array}$ & $\begin{array}{l}11.5 \\
63.6\end{array}$ & $\mathrm{Ti}^{4+}$ & 57.8 & $\mathrm{H}_{2} \mathrm{O}$ & 4.5 \\
\hline \multirow[t]{4}{*}{ Ti2_20M } & TiP & 7.3 & $\mathrm{Ti}^{2+}$ & 5.0 & $\mathrm{O}^{2-}$ & 48.2 \\
\hline & $\mathrm{P}$ & 2.6 & $\mathrm{Ti}^{3+}$ & 29.9 & $\mathrm{OH}$ & 48.4 \\
\hline & $\mathrm{P}-\mathrm{C}$ & 11.6 & $\mathrm{Ti}^{4+}$ & 65.1 & $\mathrm{H}_{2} \mathrm{O}$ & 3.4 \\
\hline & $\left(\mathrm{PO}_{4}\right)^{3-}$ & 78.5 & & & & \\
\hline \multirow[t]{4}{*}{ Ti3_30M } & TiP & 21.5 & $\mathrm{Ti}^{2+}$ & 11.7 & $\mathrm{O}^{2-}$ & 64.8 \\
\hline & $\mathrm{P}$ & 4.8 & $\mathrm{Ti}^{3+}$ & 30.5 & $\mathrm{OH}$ & 32.1 \\
\hline & $\mathrm{P}-\mathrm{C}$ & 13.9 & $\mathrm{Ti}^{4+}$ & 57.8 & $\mathrm{H}_{2} \mathrm{O}$ & 3.1 \\
\hline & $\left(\mathrm{PO}_{4}\right)^{3-}$ & 59.8 & & & & \\
\hline \multirow[t]{4}{*}{ Ti1A_10M } & TiP & 15.9 & $\mathrm{Ti}^{2+}$ & 9.6 & $\mathrm{O}^{2-}$ & 57.5 \\
\hline & $\mathrm{P}$ & 4.4 & $\mathrm{Ti}^{3+}$ & 29.1 & $\mathrm{OH}$ & 38.6 \\
\hline & P-C & 15.5 & $\mathrm{Ti}^{4+}$ & 61.3 & $\mathrm{H}_{2} \mathrm{O}$ & 3.9 \\
\hline & $\left(\mathrm{PO}_{4}\right)^{3-}$ & 64.2 & & & & \\
\hline \multirow[t]{4}{*}{ Ti2A_10M } & TiP & 16.3 & $\mathrm{Ti}^{2+}$ & 9.8 & $\mathrm{O}^{2-}$ & 51.7 \\
\hline & $\mathrm{P}$ & 3.5 & $\mathrm{Ti}^{3+}$ & 29.7 & $\mathrm{OH}$ & 40.4 \\
\hline & $\mathrm{P}-\mathrm{C}$ & 13.0 & $\mathrm{Ti}^{4+}$ & 60.5 & $\mathrm{H}_{2} \mathrm{O}$ & 7.9 \\
\hline & $\left(\mathrm{PO}_{4}\right)^{3-}$ & 67.2 & & & & \\
\hline \multirow[t]{4}{*}{ Ti3A_10M } & $\mathrm{TiP}$ & 20.8 & $\mathrm{Ti}^{2+}$ & 12.8 & $\mathrm{O}^{2-}$ & 60.1 \\
\hline & $\mathrm{P}$ & 2.3 & $\mathrm{Ti}^{3+}$ & 30.0 & $\mathrm{OH}$ & 36.7 \\
\hline & $\mathrm{P}-\mathrm{C}$ & 12.9 & $\mathrm{Ti}^{4+}$ & 57.2 & $\mathrm{H}_{2} \mathrm{O}$ & 3.2 \\
\hline & $\left(\mathrm{PO}_{4}\right)^{3-}$ & 64.0 & & & & \\
\hline \multirow[t]{4}{*}{ Ti1A_10g } & TiP & 19.2 & $\mathrm{Ti}^{2+}$ & 10.8 & $\mathrm{O}^{2-}$ & 60.8 \\
\hline & $\mathrm{P}$ & 3.3 & $\mathrm{Ti}^{3+}$ & 29.4 & $\mathrm{OH}$ & 35.4 \\
\hline & P-C & 11.8 & $\mathrm{Ti}^{4+}$ & 59.8 & $\mathrm{H}_{2} \mathrm{O}$ & 3.8 \\
\hline & $\left(\mathrm{PO}_{4}\right)^{3-}$ & 65.7 & & & & \\
\hline \multirow[t]{4}{*}{ Ti1A_20g } & TiP & 22.0 & $\mathrm{Ti}^{2+}$ & 11.2 & $\mathrm{O}^{2-}$ & 62.5 \\
\hline & $\mathrm{P}$ & 3.0 & $\mathrm{Ti}^{3+}$ & 29.2 & $\mathrm{OH}$ & 33.9 \\
\hline & P-C & 10.8 & $\mathrm{Ti}^{4+}$ & 59.6 & $\mathrm{H}_{2} \mathrm{O}$ & 3.6 \\
\hline & $\left(\mathrm{PO}_{4}\right)^{3-}$ & 64.2 & & & & \\
\hline \multirow[t]{4}{*}{ Ti1A_30g } & $\mathrm{TiP}$ & 17.0 & $\mathrm{Ti}^{2+}$ & 9.8 & $\mathrm{O}^{2-}$ & 58.7 \\
\hline & $\mathrm{P}$ & 3.3 & $\mathrm{Ti}^{3+}$ & 27.7 & $\mathrm{OH}$ & 36.3 \\
\hline & $\mathrm{P}-\mathrm{C}$ & 14.1 & $\mathrm{Ti}^{4+}$ & 62.5 & $\mathrm{H}_{2} \mathrm{O}$ & 5.0 \\
\hline & $\left(\mathrm{PO}_{4}\right)^{3-}$ & 65.6 & & & & \\
\hline
\end{tabular}

\subsection{XRD analysis}

The results of XRD qualitative phase analysis for all the PEO samples prepared in this study (Table 1) are shown in Figs. 4a, 5a and 6a, indicating a mixture of polycrystalline anatase (JCPDS 89-420) and rutile (JCPDS 76-1938) $\mathrm{TiO}_{2}$ with a low amount of amorphous phases, present throughout the deposited layers. The X-ray pattern of the substrate was identified and attributed to polycrystalline Ti- $\alpha$ phase (JCPDS 89-2762). 


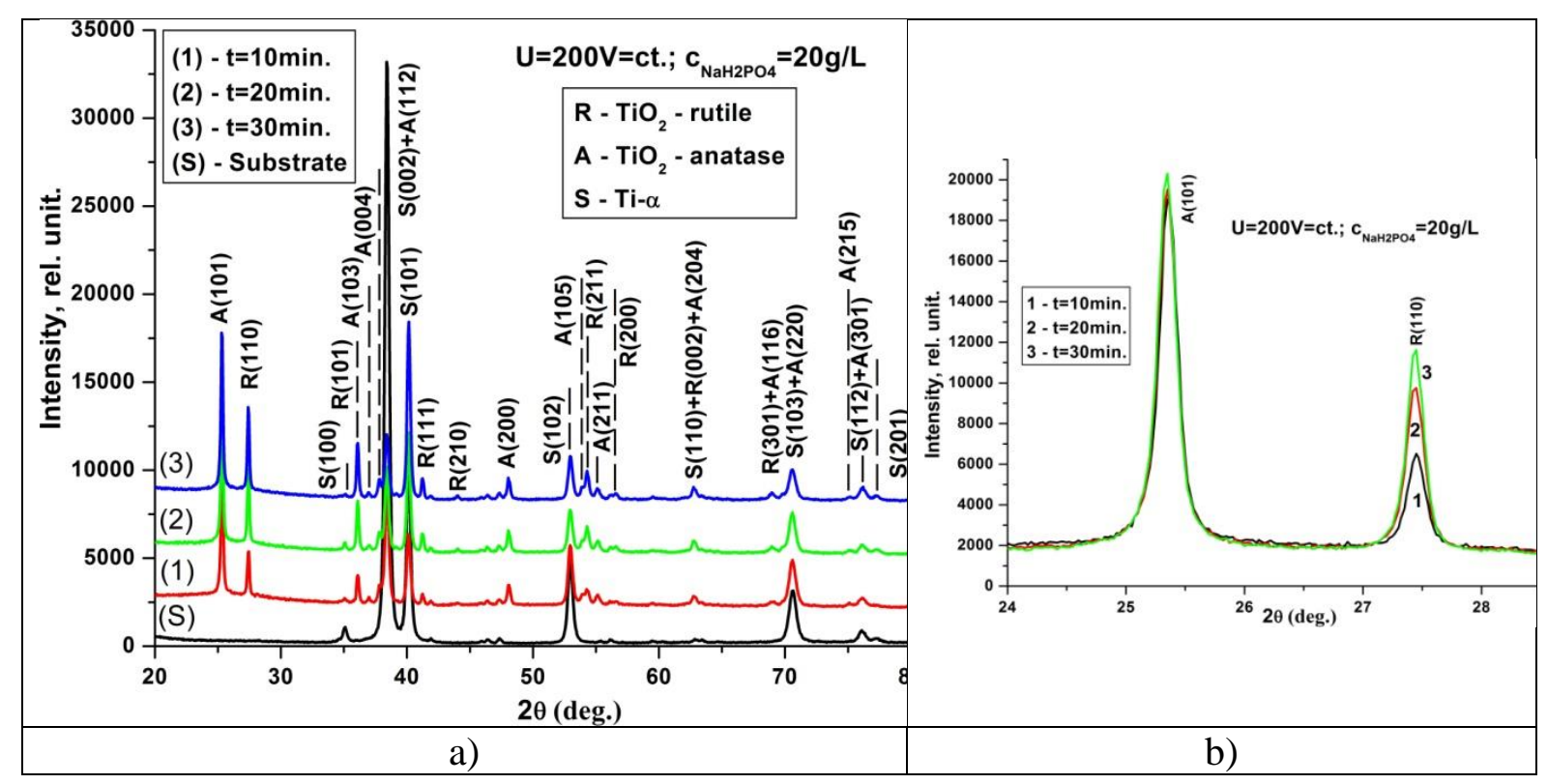

Fig. 4. X-ray diffraction patterns for the first set of samples: a) indexed XRD reflections of the PEO coatings; b) A(101) and R(110) reflections used in Spurr-Myers and Scherrer methods.

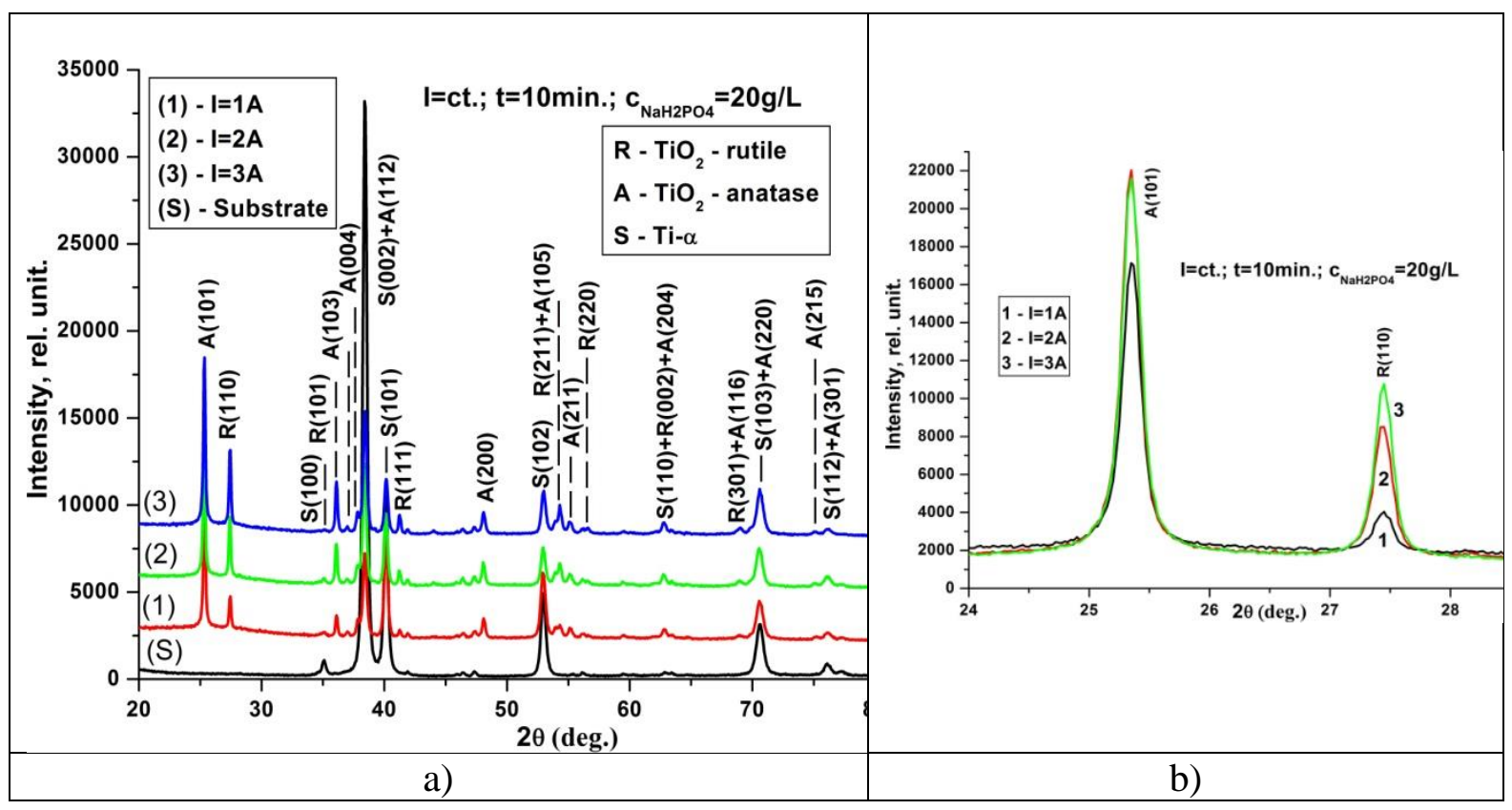

Fig. 5. X-ray diffraction patterns for the second set of samples: a) indexed XRD reflections of the PEO coatings; b) A(101) and R(110) reflections used in Spurr-Myers and Scherrer methods. 


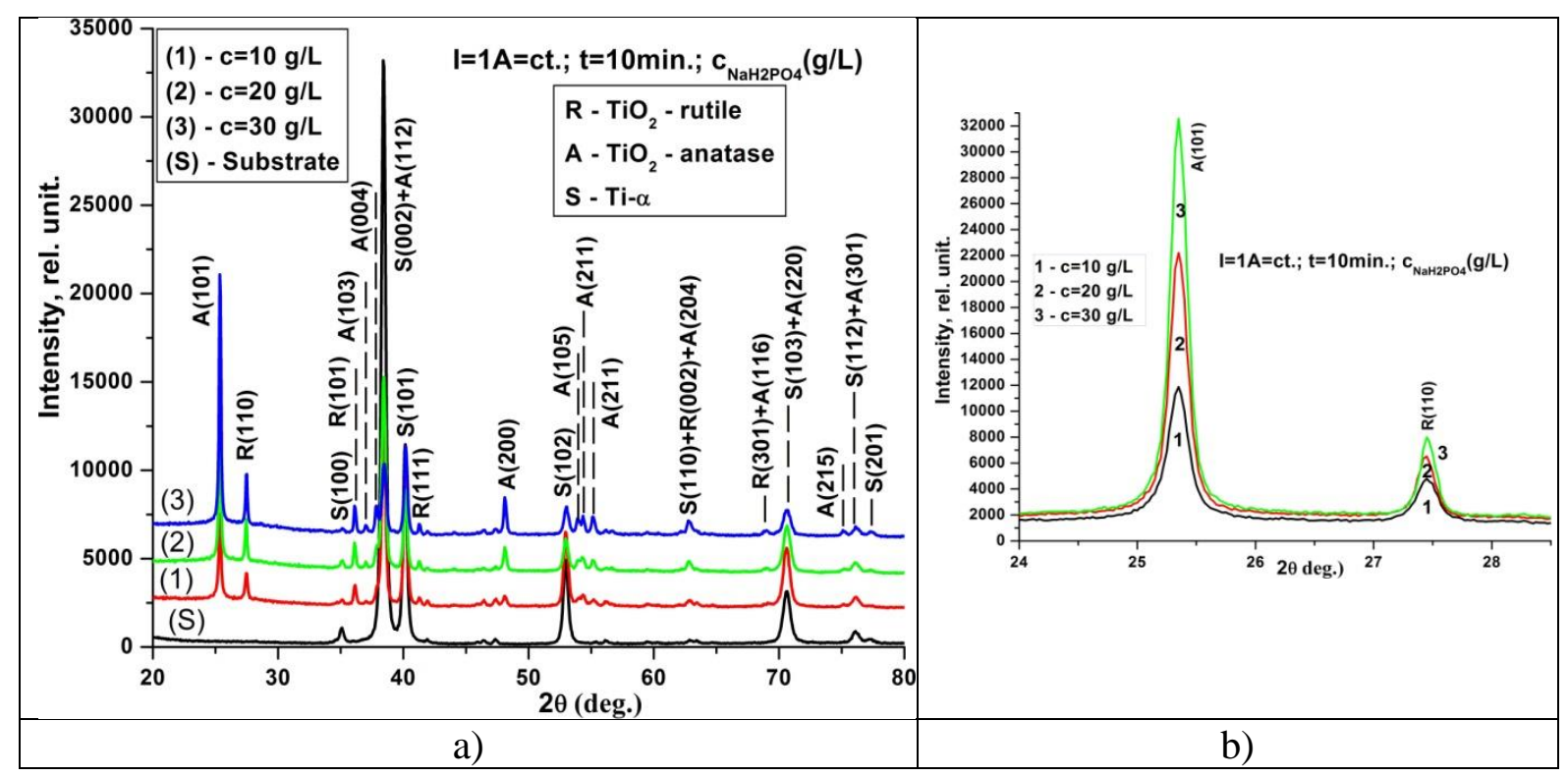

Fig. 6. X-ray diffraction patterns for the third set of samples: a) indexed XRD reflections of the PEO coatings; b) A(101) and R(110) reflections used in Spurr-Myers and Scherrer methods.

In contrast to Fig. 4a, Fig. 7 shows the superimposed diffraction patterns of the PEO layers obtained for the first set of samples after removing the X-ray diffraction peaks corresponding to the Ti substrate in order to illustrate the possible presence of amorphous phases.

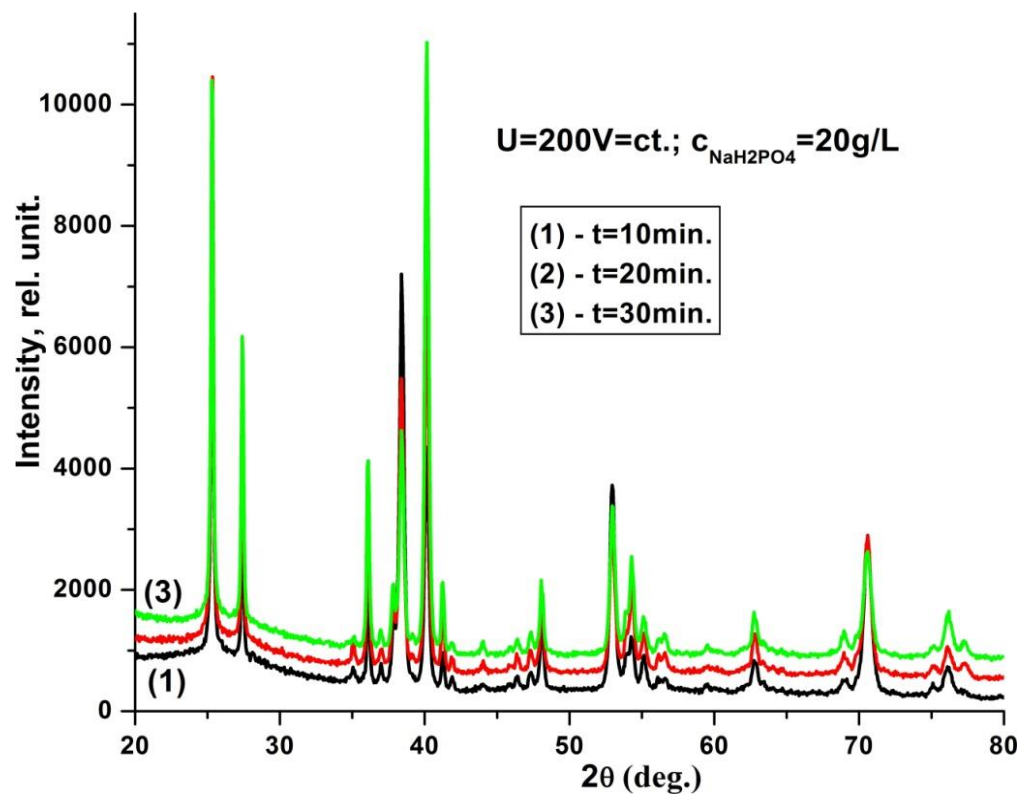

Fig. 7. X-ray diffractograms for the first set of samples without the contribution of the Ti standard pattern. 
The XRD diffractograms, shown in Fig. 7, exhibit a peak diffraction width due to amorphous phases in the angular range of $20-35^{\circ}$ found under the $100 \%$ intensity diffraction lines of polycrystalline $\mathrm{TiO}_{2}$ anatase (101) and rutile (110), respectively. A similar peak diffraction broadening can also be observed experimentally in the diffraction patterns of the PEO oxide layers deposited on the second and third set of samples (Fig. 5a and 6a). During the PEO process, a large number of micro-arc discharge channels are produced and are randomly dispersed on the sample surface when the anodic voltage exceeds the breakthrough voltage of the layer in the micro-zones of the surface. The plasma temperature is between $\sim 4500$ and $10000 \mathrm{~K}[30]$ and the micro-spark or micro-arc discharges occur for $\sim 10^{-4} \mathrm{~s}[31]$, in the electrical discharge channels (pores). Additionally, due to the very high temperatures, heating, evaporation and ionization of wall substances and bottom of the channel phenomena take place. Thus, titanium from the electrical discharge channels is subjected to the following chemical reactions [32]:

$$
\begin{aligned}
& \mathrm{Ti} \rightarrow \mathrm{Ti}^{4+}+4 e^{-} \\
& \mathrm{Ti}^{4+}+2 \mathrm{O}^{2-} \rightarrow \mathrm{TiO}_{2} \\
& \mathrm{Ti}^{4+}+x \cdot \mathrm{OH}^{-} \rightarrow\left[\mathrm{Ti}(\mathrm{OH})_{x}\right]_{g e l}^{n-} \\
& {\left[\mathrm{Ti}(\mathrm{OH})_{x}\right]_{g e l}^{n-} \rightarrow \mathrm{Ti}(\mathrm{OH})_{4}+(x-4) \cdot \mathrm{OH}^{-}} \\
& \mathrm{Ti}(\mathrm{OH})_{4} \rightarrow \mathrm{TiO}_{2}+2 \mathrm{H}_{2} \mathrm{O}
\end{aligned}
$$

Sudden cooling of the titanium dioxide formed under the above reactions as a result of the cold substrate in the vicinity and of very short time period of the electrical micro-discharges, favors the formation of both $\mathrm{TiO}_{2}$ amorphous and polycrystalline phases [10, 33]. The TEM analysis reported in [34] indicates that the $\mathrm{TiO}_{2}$ layer generated in the phosphate-containing electrolytes during PEO process shows mainly a nanocrystalline structure along with a small amount of amorphous phase. A possible hypothesis regarding the role of phosphorus in formation of amorphous phases across the PEO coatings could be described considering the occurrence of 
$\mathrm{Ti}\left(\mathrm{HPO}_{4}\right)_{2}$ and/or $\mathrm{TiPO}_{4}$ in the surface layer. For Ti( $\left(\mathrm{HPO}_{4}\right)_{2}$ polycrystalline phase (JCPDS 897024), the $94.5 \%$ and $75 \%$ intensity diffraction lines are located at $26.01^{\circ}$ and $26.19^{\circ}$, respectively, while for $\mathrm{TiPO}_{4}$ polycrystalline phase (JCPDS 86-1193), the 100\% intensity diffraction peak is found at $24.6^{\circ}$. Furthermore, incorporation of phosphorus from the electrolyte environment during the electrochemical deposition process, in the form of $\mathrm{PO}_{4}{ }^{3-}$ and TiP species, was confirmed by XPS (Figs. 1-3, Table 3). Consequently, the influence of phosphorus on film growth could be explained taking into account the above-mentioned statements, particularly the amorphous and crystalline forms of the films within the $2 \theta=20-35^{\circ}$ range as well as the attached phosphorus chemical states on the surface. It is worth stressing that a similar mechanism was proposed by Khan et al. [18].

The XRD patterns (Figs. $4 b, 5 b$ and $6 b$ ) were used to estimate the relative weight fraction of rutile $\left(\mathrm{X}_{\mathrm{R}}\right)$ and anatase $\left(\mathrm{X}_{\mathrm{A}}\right)$ using the method developed by Spurr and Myers [22]. This method is described by equation:

$$
X_{R}=\left(1+0,8 \cdot \frac{I_{A}}{I_{R}}\right)^{-1} ; \mathrm{X}_{\mathrm{A}}=1-\mathrm{X}_{\mathrm{R}}
$$

where $I_{A}$ and $I_{R}$ are the integrated $X$-ray intensities of the strongest anatase and rutile peaks corresponding to (101) anatase and (110) rutile planes at $25.3^{\circ}$ and $27.4^{\circ}$, respectively.

By fitting the diffraction peaks (Figs. 4b, 5b, 6b) with the pseudo-Voigt analytical function, the obtained integrated intensities of the reflections were used to calculate the volume fractions of rutile $\left(\mathrm{X}_{\mathrm{R}}\right)$ and anatase $\left(\mathrm{X}_{\mathrm{A}}\right) \mathrm{TiO}_{2}$ employing equation (5). The estimated results are summarized in Table 4.

\section{Table 4}

Rutile to anatase $\mathrm{TiO}_{2}$ weight fractions of the PEO coatings and crystallite size values calculated from physical integral breadth of (110) rutile and (101) anatase $\mathrm{TiO}_{2}$ diffraction lines

\begin{tabular}{ccccc}
\hline Sample code & $\mathrm{X}_{\mathrm{R}}($ wt.\% $)$ & $\mathrm{X}_{\mathrm{A}}($ wt.\% $)$ & $\mathrm{D}_{\mathrm{R}(110)}(\mathrm{nm})$ & $\mathrm{D}_{\mathrm{A}(101)}(\mathrm{nm})$ \\
\hline Ti1_10M & 23.6 & 76.4 & 70 & 45 \\
Ti2_20M & 34.1 & 65.9 & 68 & 54
\end{tabular}




\begin{tabular}{ccccc} 
Ti3_30M & 37.3 & 62.7 & 73 & 54 \\
Ti1A_10M & 20.8 & 79.2 & 61 & 56 \\
Ti2A_10M & 28.6 & 71.4 & 62 & 55 \\
Ti3A_10M & 34.0 & 66.0 & 68 & 53 \\
Ti1A_10g & 27.3 & 72.7 & 48 & 45 \\
Ti1A_20g & 20.7 & 79.3 & 65 & 56 \\
Ti1A_30g & 17.5 & 82.5 & 98 & 64 \\
\hline
\end{tabular}

One can notice an increased $\mathrm{TiO}_{2}$ anatase relative concentration, greater than $60 \%$ for all treated samples (Table 4). However, in the case of the first set of samples, prepared in the potentiostatic mode $(\mathrm{U}=200 \mathrm{~V})$, the rutile phase concentration increases with increasing PEO process time, from $23.6 \%$ to $37.3 \%$. This behavior can be explained by the increase of the electric current intensity during the deposition procedure, in the range of 1-1.2A, 1-2.2A and 1-3A (effective values) for $10 \mathrm{~min}, 20 \mathrm{~min}$ and $30 \mathrm{~min}$ time intervals, respectively. Simultaneously, an enrichment of the rutile phase content as a result of current intensity increase can be also observed when the galvanostatic regime was applied for the second set of samples $(\mathrm{I}=1 \mathrm{~A} ; 2 \mathrm{~A} ; 3 \mathrm{~A})$. The tendency of rutile $\mathrm{TiO}_{2}$ content increase with current intensity increase under constant concentration of electrolyte has been previously reported [10]. In the above-mentioned paper, the authors electrolytically oxidized CP-Ti under galvanostatic conditions by applying current densities of 5, 10, 15 and $20 \mathrm{~A} / \mathrm{dm}^{2}$ in a solution of 5,10 and $15 \mathrm{~g} / \mathrm{L}$ trisodium orthophosphate $\left(\mathrm{Na}_{3} \mathrm{PO}_{4}\right)$ for a fixed duration of $10 \mathrm{~min}$. All electrolyte concentration values favored an enhanced rutile $\mathrm{TiO}_{2}$ phase formation with increasing current density.

By contrast, an opposite trend was observed for the third set of samples which were prepared under galvanostatic regime $(\mathrm{I}=1 \mathrm{~A})$ such that a decrease of rutile $\mathrm{TiO}_{2}$ phase content, from $27.3 \%$ to $17.5 \%$, with the increase of electrolyte solution concentration occurs. This behavior was also described by [10]. In as much as the electric current density and the duration of PEO treatment have the same values, it results that inhibition of anatase to rutile transformation is due to the presence of phosphorus in the coating layers. 
Additionally, the authors argue the above-mentioned mechanisms giving a further possible explanation for their experimental observations. Thereby, analysis of the existing data in the literature and our recent experimental results on relative mass concentration of rutile and anatase $\mathrm{TiO}_{2}$ phases in the PEO coatings deposited on commercially pure titanium using basic electrolytes containing sodium phosphates indicated that there are no significant differences between these values and those obtained by the present authors, from acid electrolytes. Thus, in the current study, the authors assessed the rutile concentration within Ti1A_10g sample and calculated an amount of $27.3 \%$ (Table 4) obtained on CP-Ti grade 2 in $10 \mathrm{~g} / \mathrm{L} \mathrm{NaH} \mathrm{PO}_{4} \cdot 2 \mathrm{H}_{2} \mathrm{O}$ aqueous acidic electrolyte solution $(\mathrm{pH}=5.0)$. In the work of $\mathrm{Chu}$ [17], the PEO layers obtained on CP-Ti grade 2 in aqueous solution of basic electrolyte containing $0.04 \mathrm{M} \mathrm{NaH}_{2} \mathrm{PO}_{4} \cdot 2 \mathrm{H}_{2} \mathrm{O}$ and $0.5 \mathrm{M} \mathrm{NaOH}(\mathrm{pH}=9.8)$ yield a $\mathrm{TiO}_{2}$-rutile relative mass concentration of $\sim 30 \%$. This finding is in excellent agreement with the $I_{A}(101) / I_{R}(110)=3$ ratio calculated from [17]. The PEO treatment was performed in a potentiostatic mode $\left(\mathrm{U}_{\mathrm{amp}}=500 \mathrm{~V}\right)$, by applying unipolar pulses. A similar result was obtained by Khan [18], which prepared oxidic layers on CP-Ti grade 2 under galvanostatic regime $\left(\mathrm{j}=10 \mathrm{~A} / \mathrm{dm}^{2}\right)$, using unipolar pulses with a frequency ranging from 0.1 to $1 \mathrm{KHz}$ and duty cycles between 20 and $80 \%$, for a treatment duration of 10 minutes. The aqueous basic electrolyte solution used contained $10 \mathrm{~g} / \mathrm{L} \mathrm{Na} \mathrm{PO}_{4} \cdot 12 \mathrm{H}_{2} \mathrm{O}$. The sample developed under a $v=100 \mathrm{~Hz}$ and $\eta=40 \%$ experimental conditions yielded a rutile $\mathrm{TiO}_{2}$ relative concentration of $\sim 23 \%$.

The high voltage and temperature [30] involved during the electrochemical PEO process can led to a migration of phosphate ions originating from the electrolyte into the growing film, penetrating the oxide layer, favoring the incorporation of phosphorus on titanium surface [35]. The above theoretical assumptions have been proven by means of surface and subsurface experimental observation. Thus, the XPS and EDS analysis validated the presence and chemical state of the integrated phosphorus through the coating layer. Moreover, the optical 
metallography further confirmed the existence of the PEO layer on the metal substrate, ranging from 2.9 to $10.8 \mu \mathrm{m}$ (Table 6).

On the other hand, the effect of phosphate ions incorporated into the surface coating can be linked with an inhibiting mechanism of anatase-rutile transformation. This can be interpreted as a suppression of anatase particles growth by limiting the contact between anatase particles and thus, blocking the formation of conglomerates, the rutile phase being associated with an increased particle size [14]. An experimental confirmation of this statement can be seen in Table 4, where the rutile crystallites were found larger than anatase crystallites.

The crystallite sizes of the polycrystalline $\mathrm{TiO}_{2}$ rutile and anatase phases were calculated from the pure-specimen integral breadth of the $\mathrm{A}(101)$ and $\mathrm{R}(110)$ diffraction peaks using modified Scherrer formula $[23,36]$ :

$$
D_{h k l}=\frac{K_{S} \cdot \lambda}{\beta_{h k l} \cdot \cos \theta_{h k l}}
$$

where $D_{\text {hkl }}$ is the volume weighted crystallite size $(\mathrm{nm}) ; K_{S}$ is Scherrer constant; $\lambda$ is the wave length of the X-rays ( $\lambda=0.154056 \mathrm{~nm}$ for $\mathrm{Cu} \mathrm{K}_{\alpha 1}$ radiation); $\theta_{\mathrm{hkl}}$ is Bragg diffraction angle ( $\left.{ }^{\circ}\right)$ and $\beta_{\mathrm{hkl}}$ is the integral breadth of physical profile (hkl) diffraction peak (in radians).

The integral breadth of physical profiles $\left(\beta_{\mathrm{fA}}\right)$ and $\left(\beta_{\mathrm{fR}}\right)$ for the (101) anatase and (110) rutile diffraction lines of $\mathrm{TiO}_{2}$ were estimated by Fourier analysis of experimental and instrumental profiles. The Scherrer constant was assumed to be $\mathrm{K}_{S}=(4 / 3)^{*}(\pi / 6)^{1 / 3}=1.0747$ [36] for spherical crystallite. Calculated values of crystallite sizes are shown in Table 4.

The crystallite size values for anatase are lower than for rutile in all the investigated samples. Significant variations in crystallite size were evidenced for the third set of samples at which the anatase phase varies between 45-64 $\mathrm{nm}$ and the crystallite size for the rutile phase varies from 48 to $98 \mathrm{~nm}$. Moreover, when increasing the electrolyte concentration, the difference between anatase and rutile crystallite size increases, from 3 to $34 \mathrm{~nm}$ (Table 4). A similar crystallite size of 40 and $45 \mathrm{~nm}$ for anatase and rutile, respectively was calculated by Chu and 
co-workers [33] when pure Ti was PEO oxidized using an electrolyte bath containing $0.04 \mathrm{M}$ $(6.24 \mathrm{~g} / \mathrm{L})$ sodium dihydrogen phosphate dihydrate $\left(\mathrm{NaH}_{2} \mathrm{PO}_{4} \cdot 2 \mathrm{H}_{2} \mathrm{O}\right)$ and $0.5 \mathrm{M} \mathrm{NaOH}$ solution at $\mathrm{pH}$ 9.8. According to Khan et al. [18] 32 and $36 \mathrm{~nm}$ crystallite size values for anatase and rutile, respectively were obtained on CP-Ti samples under galvanostatic conditions $(\mathrm{j}=10$ $\mathrm{A} / \mathrm{dm}^{2}$ ) for $10 \mathrm{~min}$ in $10 \mathrm{~g} / \mathrm{L} \mathrm{Na} \mathrm{PO}_{4} \cdot 12 \mathrm{H}_{2} \mathrm{O}$ electrolyte solution.

\subsection{SEM/EDS surface morphology of the PEO coatings}

SEM micrographs of the PEO coated samples are illustrated in Figs. 8-10. During potentiostatic growth of the films, the coating surface morphology is influenced by the deposition time period. Thus, from low-magnification images, it can be seen a decreasing density of pores with increasing PEO duration time (Fig. 8a, c, e). On the other hand, there is an increasing pore size with increasing treatment time, from 1.1-1.4 $\mu \mathrm{m}$ to 1.2-2.9 $\mu \mathrm{m}$. Additionally, the crater-like morphology with smooth surrounding surface occurs for all deposition times probably due to melting and solidification of the material as a consequence of abrupt change upon heating and cooling attributed to discharging activity from the PEO process $[10,18]$. The nanograined structure of the surface was observed at high-magnification (Fig. 8b, d, f), clearly indicating an uniform grains distribution tendency and uniform average grain sizes with increasing treatment time period.

In contrast to the first set of samples, prepared in potentiostatic mode, the applied galvanostatic regime impose different changes in surface morphology for samples subjected to increasing current densities (Fig. 9). Thus, a mixture of grains and pores with varying dimensions and densities are shown in high-magnification images (Fig. 9b, d, f). The crater-like surface porosity with smooth edges visualized in the micron range (Fig. 9a, c, e) indicates an increasing pore sizes and pore volumes with increasing electric current density. Thus, a pore size of about 305-870 $\mathrm{nm}$ to $1.5-1.8 \mu \mathrm{m}$ was noticed during higher discharge currents. This can also be 
explained by the rapid heating and cooling rates combined with melting and resolidification of the coating material due to microdischarging processes [10].

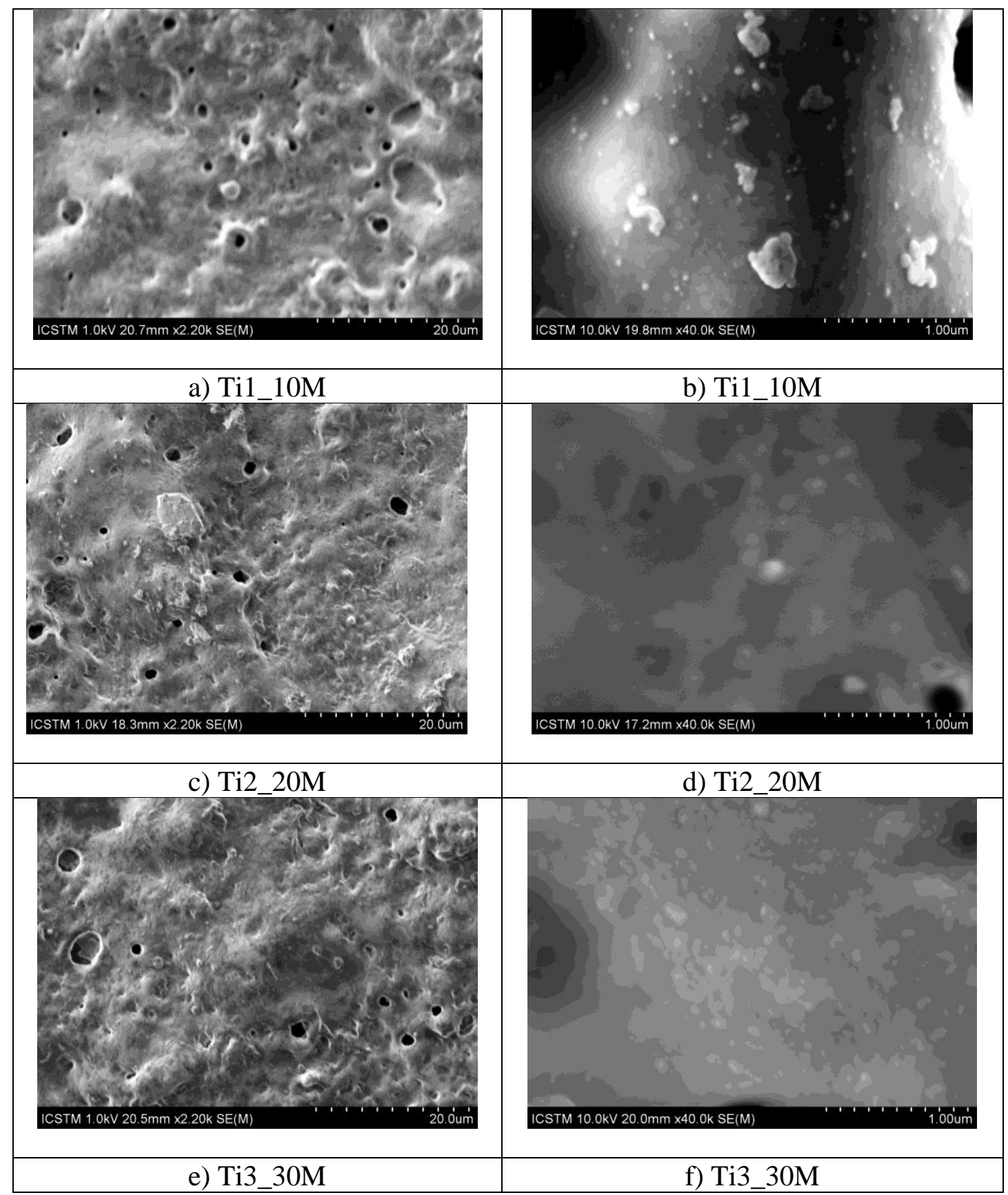

Fig. 8. SEM micrographs for the first set of samples after 10, 20 and 30 min PEO process time: low magnification (a, c, e); high magnification (b, d, f). 


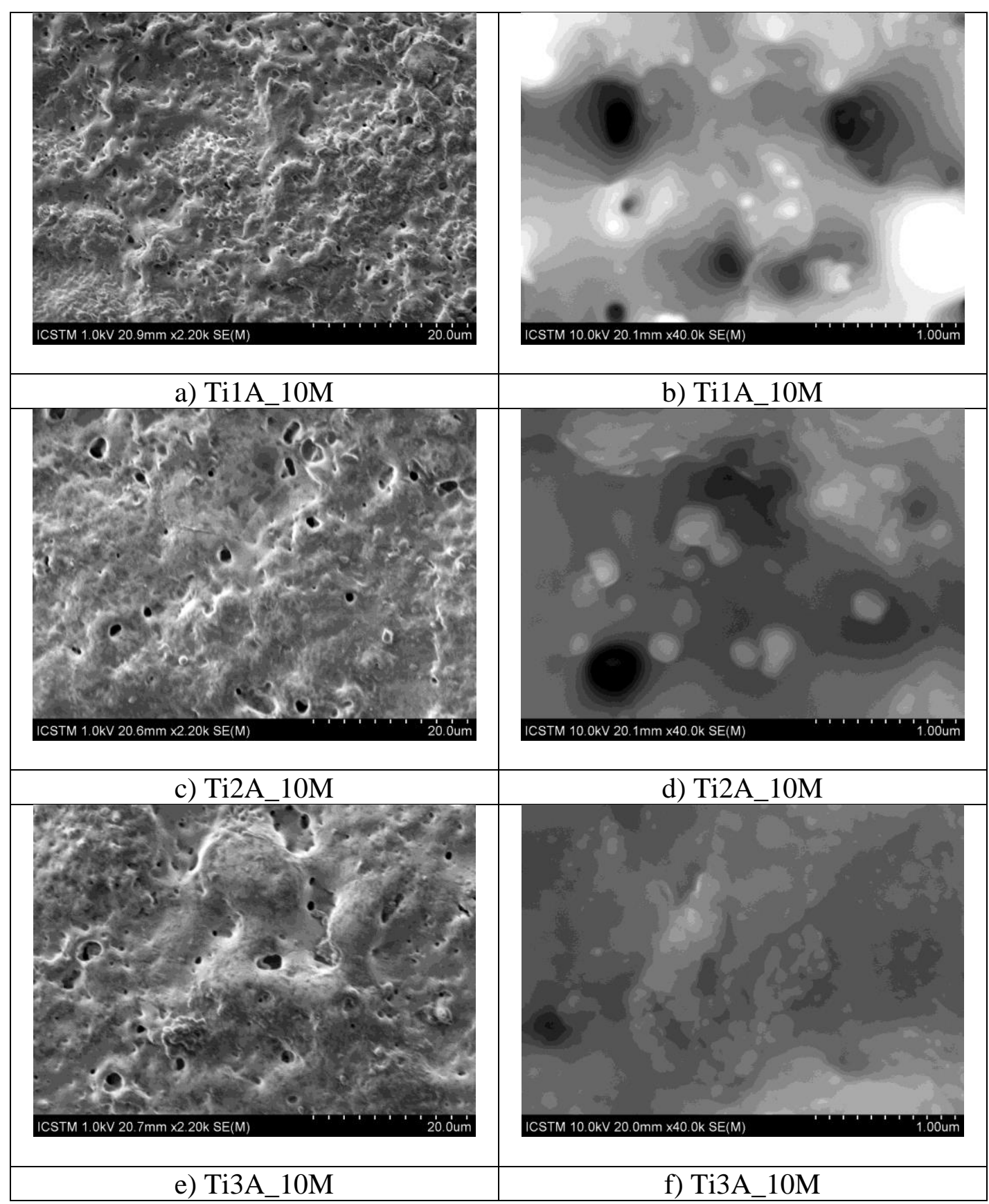

Fig. 9. SEM micrographs for the second set of samples after 1, 2 and 3 A oxidation current intensities: low magnification (a, c, e); high magnification (b, d, f).

An overview SEM image of the third set of samples (Fig. 10a, c, e) shows an increasing surface porosity together with increasing electrolyte concentration. Simultaneously, the nanograins size decreases when electrolyte concentration increases (Fig. 10b, d, f). As a conclusion, the electrolyte concentration has an impact on surface morphology of the coatings leading to the 
formation of low amount of pores with a high concentration of nanograins (Fig. 10c, d) and vice versa, high concentration of pores accompanied by low amount of nanograins (Fig. 10e, f), this behavior being influenced by electrolyte concentration variation. The pore dimension ranged from $464 \mathrm{~nm}$ to $3.1 \mu \mathrm{m}$.

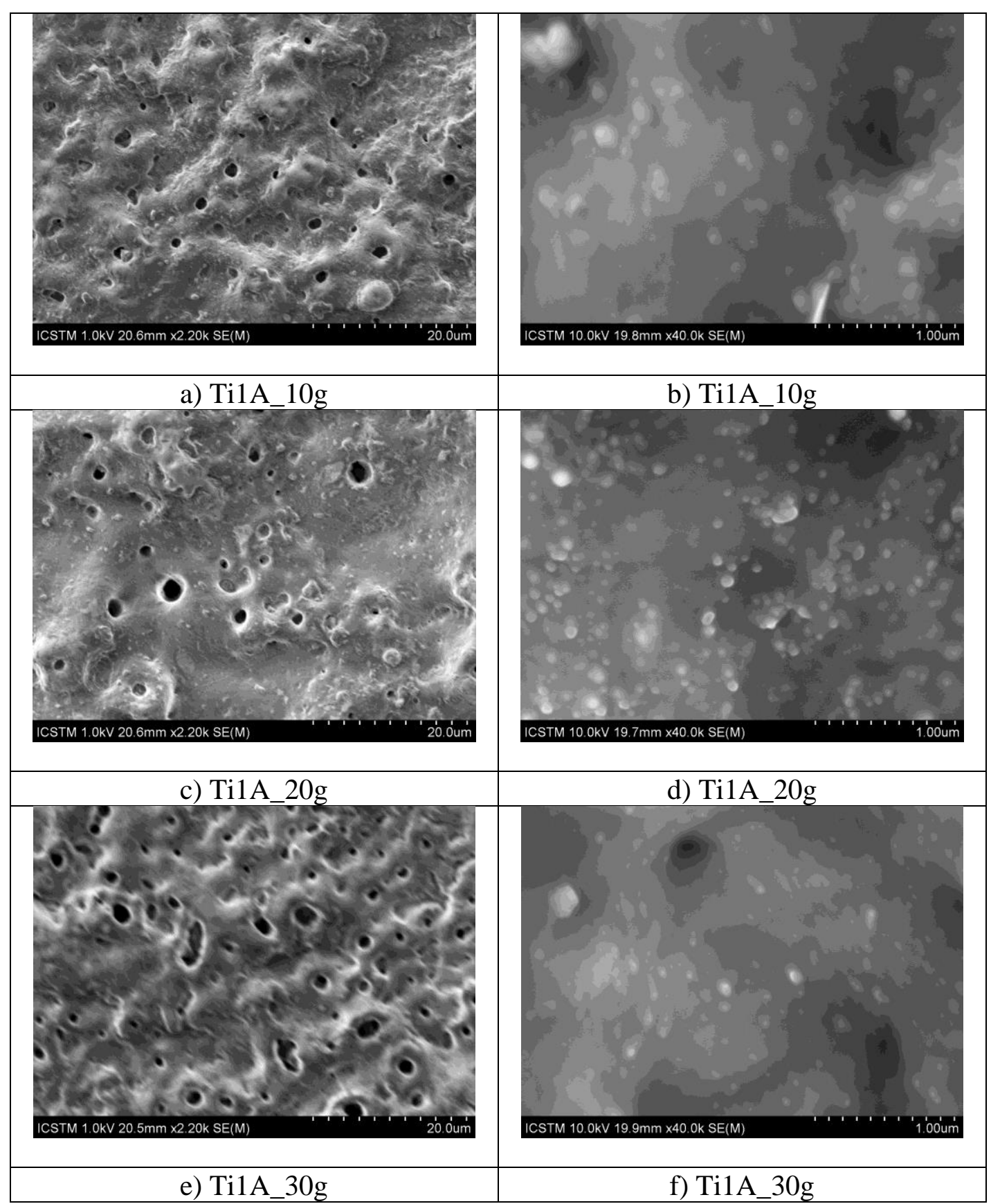

Fig. 10. SEM micrographs for the third set of samples prepared under 10,20 and $30 \mathrm{~g} / \mathrm{L}$

electrolyte concentration: low magnification (a, c, e); high magnification (b, d, f). 


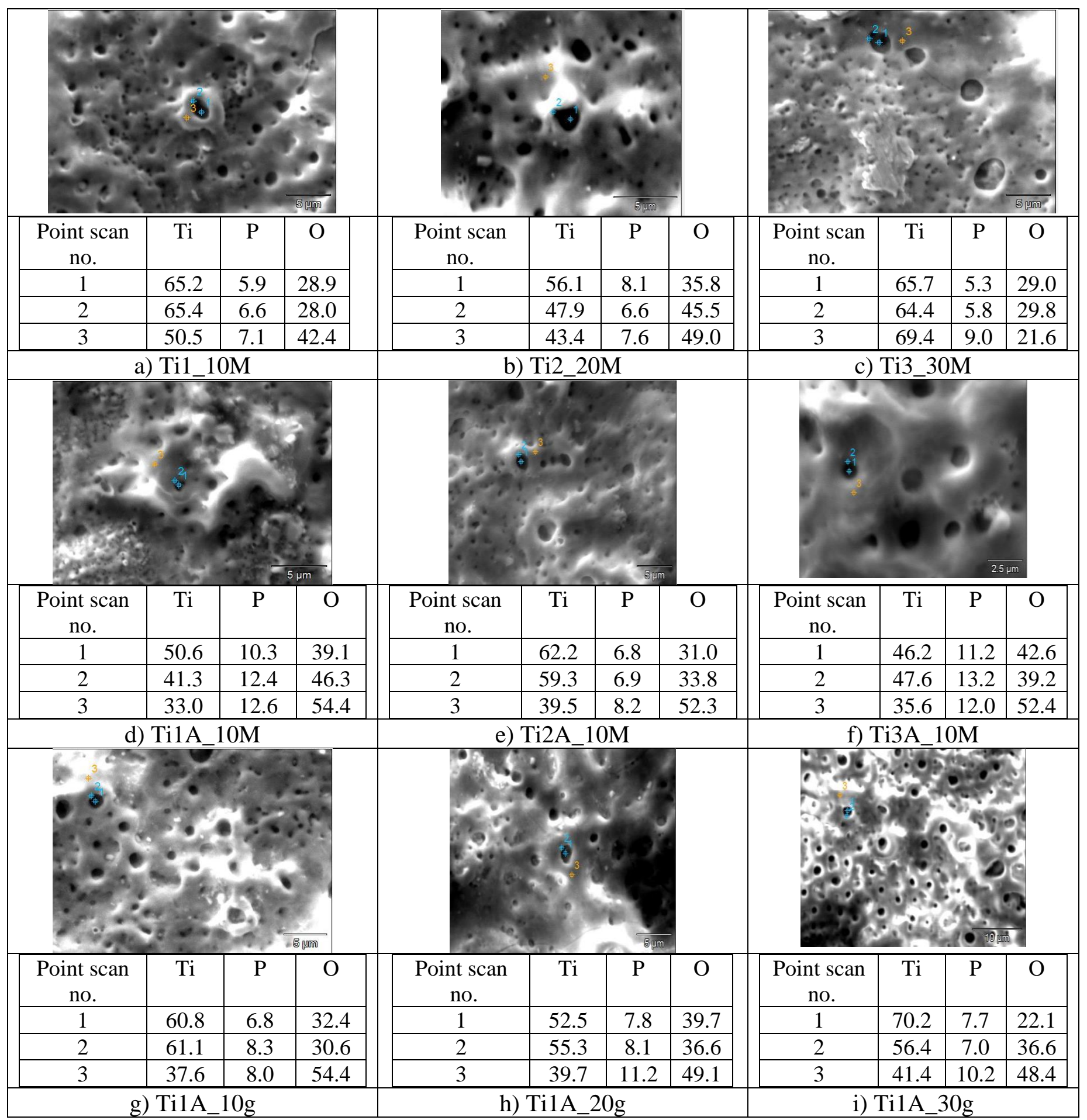

Fig. 11. Surface micrograph of the PEO coatings for the three sets of experiments and point

element mass concentrations.

Apparently, by increasing process time, oxide growth is accelerated as the oxygen concentration increases from $\sim 28 \%$ to $49 \%$ (Fig. 11a, b), except for the 30 min treatment period 
(Fig. 11c) which suggests a decreased oxygen content ( 29\%). As expected, the lowest oxygen values are found inside the pores of the coatings, near the substrate, regardless of the deposition regime used. Phosphorus was successfully embedded into the layer with a concentration of 6-8\%. In contrast to the first set of samples, the PEO treatment achieved by increasing the current density contributes to an enriched oxygen content (Fig. 11f) as compared to the samples prepared for 30 min oxidation time (Fig. 11c). Furthermore, a higher phosphorus amount ( 7$13 \%)$ was incorporated during this galvanostatic electrodeposition. Although an increasing electrolyte concentration was employed for the last set of samples, no dramatic incorporation of phosphorus into the coating layer was observed (Fig. 11g, h, i). However, from the EDS quantitative analysis, best oxide coatings were obtained under both galvanostatic conditions (second and third set of samples), phosphorus and oxygen chemical elements being enhanced while titanium was inhibited, proving the formation of a protective oxide film. Additionally, a further XPS surface quantitative evaluation confirms the above near-surface EDS composition, phosphorus and oxygen being detected at a concentration of $\sim 10$ and $67 \%$, respectively, on the outermost surface layer (Table 2).

Calculated EDS concentrations (Table 5) indicate the chemical distribution of elements within the coatings, suggesting an increasing amount of phosphorus with the increase of electrolyte concentration followed by a decreasing relative mass concentration of rutile $\mathrm{TiO}_{2}$. These findings highlight the inhibiting role of phosphorus throughout the coating layers. Detected phosphorus concentration was $\sim 10 \%$ for all treated samples, in excellent agreement with XPS measurements (Table 2).

Table 5

Element relative concentrations (wt.\%) for all PEO samples.

$\begin{array}{llll}\text { Sample } & \text { Ti (wt.\%) } & \text { P (wt.\%) } & \text { O (wt.\%) }\end{array}$




\begin{tabular}{|c|c|c|c|}
\hline & \multicolumn{3}{|c|}{ First set of samples (potentiostatic regime $U=200 \mathrm{~V}=$ constant) } \\
\hline Ti1_10M & 41.0 & 10.0 & 49.0 \\
\hline Ti2_20M & 43.8 & 8.9 & 47.3 \\
\hline Ti3_30M & 46.8 & 7.5 & 45.7 \\
\hline & \multicolumn{3}{|c|}{$\begin{array}{l}\text { Second set of samples (galvanostatic regime [I=constant }(1 \mathrm{~A} ; 2 \mathrm{~A} ; 3 \mathrm{~A}) \text {; } \\
20 \mathrm{~g} / \mathrm{L}]\end{array}$} \\
\hline Ti1A_10M & 42.8 & 11.3 & 45.9 \\
\hline Ti2A_10M & 42.8 & 9.0 & 48.2 \\
\hline Ti3A_10M & 42.0 & 10.4 & 47.6 \\
\hline & \multicolumn{3}{|c|}{$\begin{array}{l}\text { Third set of samples (galvanostatic regime } \mathrm{I}=1 \mathrm{~A}=\text { constant; } 10,20 \text { and } \\
30 \mathrm{~g} / \mathrm{L} \text { ) }\end{array}$} \\
\hline Ti1A_10g & 41.9 & 8.7 & 49.4 \\
\hline Ti1A_20g & 37.3 & 9.6 & 53.1 \\
\hline Ti1A_30g & 42.4 & 10.9 & 46.7 \\
\hline
\end{tabular}

\subsection{Layer thickness}

Results of the metallographic examinations (Table 6, Fig. 13) confirm the PEO layer formation on CP-Ti substrate and, at the same time, estimate the thickness of the oxide films. The metallographic thickness measurements given in Table 6 indicate no major discrepancy between the coatings, within the range of 3-10 $\mu \mathrm{m}$. However, the influence of experimental deposition conditions can be noticed for each sample set and also between the three sets of experiments. Thereby, the process time has an influence on oxide growth and slightly increases the layer thickness. Also, the current density induces a tiny increase in thickness. Additionally, the effect of electrolyte concentration is reflected in an increase in thickness of the prepared coatings. A brief review of the literature with respect to oxide layer thicknesses highlights a roughly $10 \mu \mathrm{m}$ thick coating formed on CP-Ti in phosphate-based electrolytes, well consistent with our measured values (Table 6) $[10,11,16,18]$. 


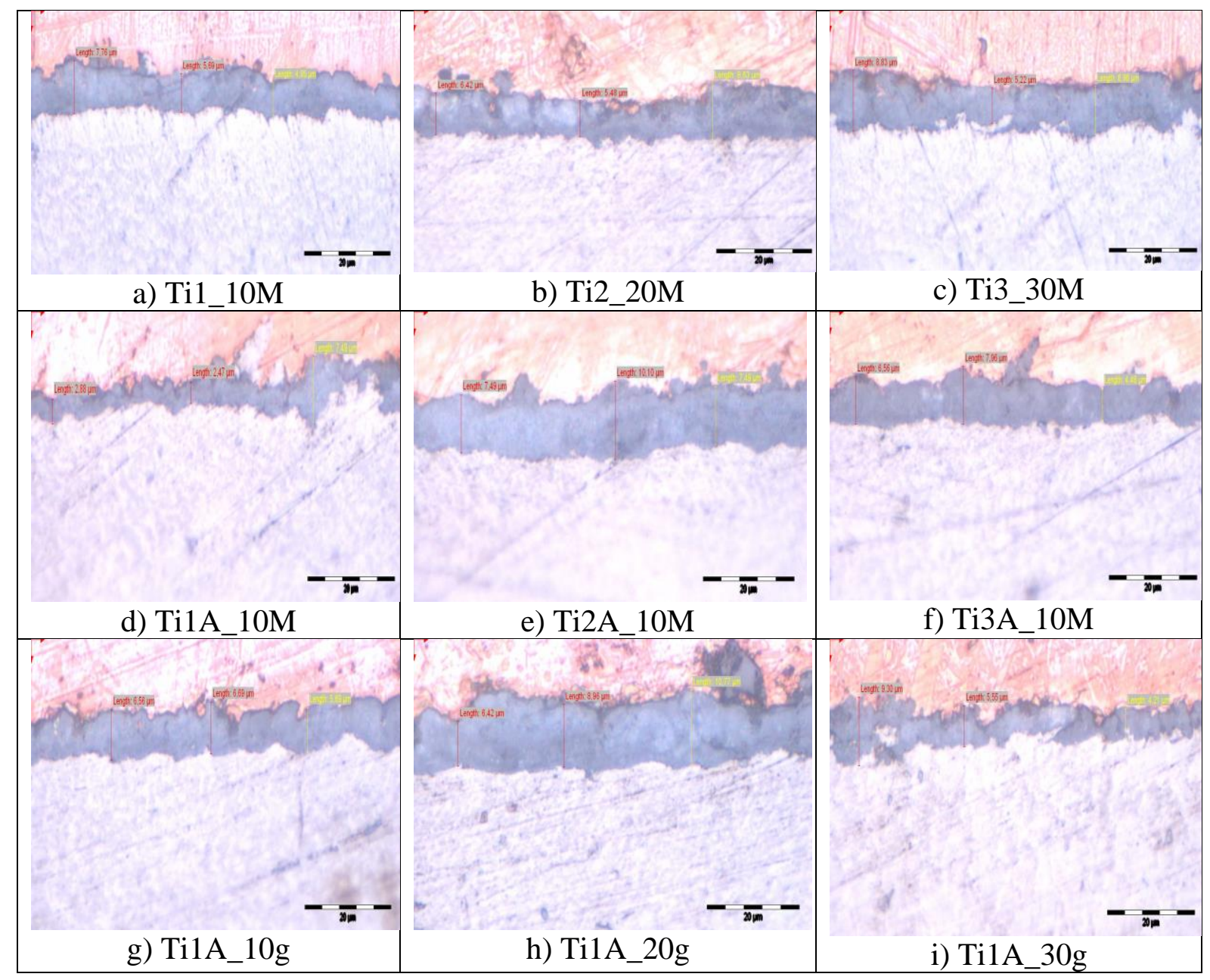

Fig. 12. Metallographic images of polished cross-sections of the investigated PEO coatings

for the three sets of experiments.

\subsection{Microhardness}

The hardness results obtained from a three point arithmetic average measured along the coating surface were summarized in Table 7. Firstly, as it can be seen in Table 7, the microhardness of the prepared layers is maintained between 300 and $453 \mathrm{HV}$, respectively, all the experimental values found being higher than that of the pure Ti substrate. Furthermore, one can notice an increasing hardness tendency which can be correlated with increasing time exposure to oxidizing conditions and electric current density for the first and second set of samples, respectively. In contrast, with increasing electrolyte concentration the hardness decreases for the last set of samples. The hardness behavior can be linked to increased or decreased presence 
of rutile (Table 6). The highest hardness recorded was $453 \mathrm{HV}$ for $30 \mathrm{~min}$ process time. Although there is a lack of data on microhardness of PEO oxide layers, we have found some additional values for comparison with our experimental results. Thus, Yerokhin reported previously a lower hardness of $\sim 349 \mathrm{HV}(\sim 360 \mathrm{HK})$ for the oxide films deposited on Ti-6Al$4 \mathrm{~V}$ alloy obtained in phosphate solution, possibly caused by the occurrence of $\mathrm{TiO}_{2}$ anatase phase. Higher values of microhardness were observed in samples prepared from aluminatephosphate and aluminate-silicate electrolytes [37]. Tekin and coworkers [38] have shown a 408 HV value for the PEO coatings developed on CP-Ti in silicate-phosphate solution. It can be seen that the literature data does not exceed the best values obtained in the present work.

\subsection{Adhesion strength}

Critical loads of adhesive failure $\left(\mathrm{L}_{\mathrm{C} 2}\right)$ and full delamination $\left(\mathrm{L}_{\mathrm{C} 3}\right)$ of the coatings are summarized in Table 7.

Similar to the above hardness results, the scratch resistance testing of the coatings show that electrochemical deposition parameters influence the adhesion of oxide layers to the metal substrate. Therefore, the surprising trend indicates an increasing adhesion resistance with increasing treatment duration and electric current density. By increasing the electrolyte concentration, the delamination strength decreases. The obtained critical load values can be also related to the rutile transformation behavior (Table 6). Best adhesion resistance performance was obtained at 30 min PEO duration time. Just as with microhardness, the little literature found on scratch behavior show only the $\mathrm{L}_{\mathrm{C} 2}$ critical loads with values of $\sim 23$ and 5 $\mathrm{N}$ for Ti-6Al-4V and CP-Ti materials, respectively, obtained in phosphate-based electrolytes $[37,38]$. Additionally, Gowtham et al. reported an increasing delamination resistance, from 15 $\mathrm{N}$ to $26 \mathrm{~N}$ when two different duty cycles and current frequencies were applied for $8 \mathrm{~min}$ in a trisodium orthophosphate with added potassium hydroxide electrolyte solution [39]. 
Table 6

PEO coating thickness, microhardness and critical load values for the three sets of experiments.

\begin{tabular}{ccccc}
\hline Sample code & $\begin{array}{c}\text { Layer thickness } \\
(\mu \mathrm{m})\end{array}$ & $\mathrm{HV}_{300}$ & $\begin{array}{c}\left(\mathrm{L}_{\mathrm{C} 2}\right) \\
(\mathrm{N})\end{array}$ & $\begin{array}{c}\left(\mathrm{L}_{\mathrm{C} 3}\right) \\
(\mathrm{N})\end{array}$ \\
\hline CP-Ti substrate & - & 253 & - & - \\
Ti1_10M & $5.0-7.8$ & 390 & 11 & 13 \\
Ti2_20M & $5.5-8.6$ & 409 & 13 & 17 \\
Ti3_30M & $5.2-8.8$ & 453 & 19 & 38 \\
Ti1A_10M & $2.9-7.5$ & 300 & 4 & 8 \\
Ti2A_10M & $7.5-10.1$ & 370 & 7 & 11 \\
Ti3A_10M & $4.5-8.0$ & 330 & 7 & 13 \\
Ti1A_10g & $5.7-6.7$ & 407 & 8 & 14 \\
Ti1A_20g & $6.4-10.8$ & 378 & 4 & 15 \\
Ti1A_30g & $4.2-9.3$ & 374 & 6 & 10 \\
\hline
\end{tabular}

\subsection{Potentiodynamic polarization tests}

Figs. 13-15 plot the potentiodynamic polarization curves of the assessed samples in Ringer's physiological solution at room temperature. A detailed inspection of Table 7 indicates a superior corrosion resistance of the newly developed coating layers against pure $\mathrm{Ti}$. Simultaneously, for the first set of samples, the corrosion current density of the PEO-coated samples decreases with increasing treatment time, from $280 \times 10^{-3}$ to $60.0 \times 10^{-3} \mu \mathrm{A} / \mathrm{cm}^{2}$ whilst the rutile phase concentration increases, from $23.6 \%$ to $37.3 \%$ (Tables 6,7 ) for 10 and 30 min process time, respectively. Secondly, similarly to what observed above, the corrosion resistance was improved with the increase of electric current density when the galvanostatic regime was applied for the second set of samples, for a fixed duration of $10 \mathrm{~min}$, accompanied also by an enrichment of the rutile phase content (Table 6,7). Nevertheless, an opposite corrosion behavior occurs for the third set of samples when the electrolyte concentration increases. At the same time, the rutile phase amount decreases with the increase of electrolyte solution concentration. The best anticorrosion properties of the tested coatings was achieved under galvanostatic regime at 3 A current intensity and 10 min PEO time yielding a corrosion current density value of $20 \times 10^{-3} \mu \mathrm{A} / \mathrm{cm}^{2}$, which is 70 times lower than the value for the untreated CPTi. Additionally, all the PEO-coated samples in this work exhibit a corrosion current density 
lower with one order of magnitude than those reported in similar studies using PEO-oxidized CP-Ti samples in sodium phosphate-based electrolytes and subjected to Ringer's physiological solution $[11,16]$.

\section{Table 7}

Results of potentiodynamic polarization tests in Ringer's physiological solution at room temperature.

\begin{tabular}{cccc}
\hline Sample code & $\mathrm{E}_{\text {corr }}(\mathrm{mV})$ & $\mathrm{i}_{\text {corr }}\left(\mu \mathrm{A} / \mathrm{cm}^{2}\right)$ & $\mathrm{V}_{\text {corr }}(\mathrm{mmpy})$ \\
\hline CP-Ti substrate & -719 & $1400 \times 10^{-3}$ & $1740 \times 10^{-4}$ \\
Ti1_10M & -177 & $280 \times 10^{-3}$ & $837 \times 10^{-4}$ \\
Ti2_20M & -242 & $210 \times 10^{-3}$ & $208.7 \times 10^{-4}$ \\
Ti3_30M & -116 & $60.0 \times 10^{-3}$ & $65.2 \times 10^{-4}$ \\
Ti1A_10M & -310 & $270 \times 10^{-3}$ & $209.1 \times 10^{-4}$ \\
Ti2A_10M & -194 & $190 \times 10^{-3}$ & $139.7 \times 10^{-4}$ \\
Ti3A_10M & -31 & $20 \times 10^{-3}$ & $16.0 \times 10^{-4}$ \\
Ti1A_10g & -118 & $90 \times 10^{-3}$ & $44.2 \times 10^{-4}$ \\
Ti1A_20g & -250 & $250 \times 10^{-3}$ & $206.2 \times 10^{-4}$ \\
Ti1A_30g & -395 & $360 \times 10^{-3}$ & $509.5 \times 10^{-4}$
\end{tabular}




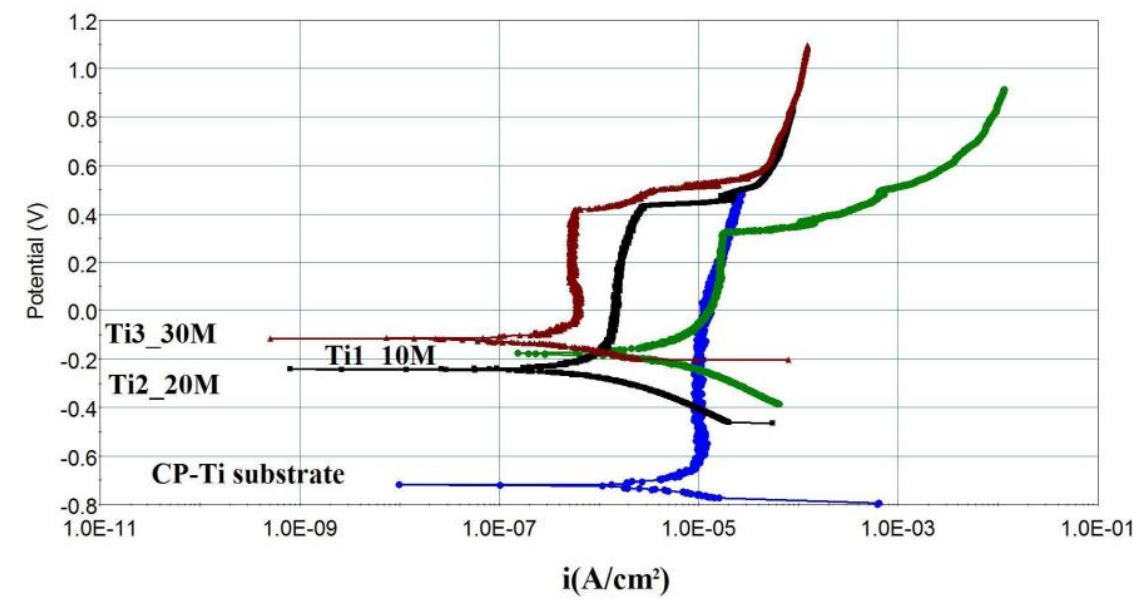

Fig. 13. Potentiodynamic polarization curves of the tested samples: CP-Ti substrate, Ti1_10M, Ti2_20M and Ti3_30M samples.

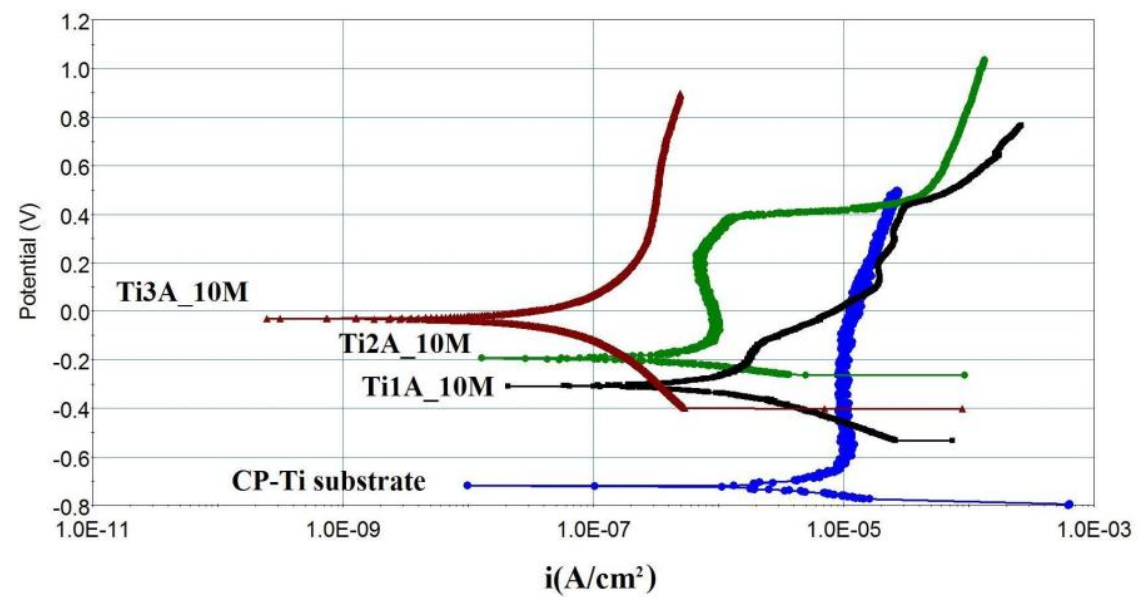

Fig. 14. Potentiodynamic polarization curves of the tested samples: CP-Ti substrate, Ti1A_10M, Ti2A_10M and Ti3A_10M samples. 


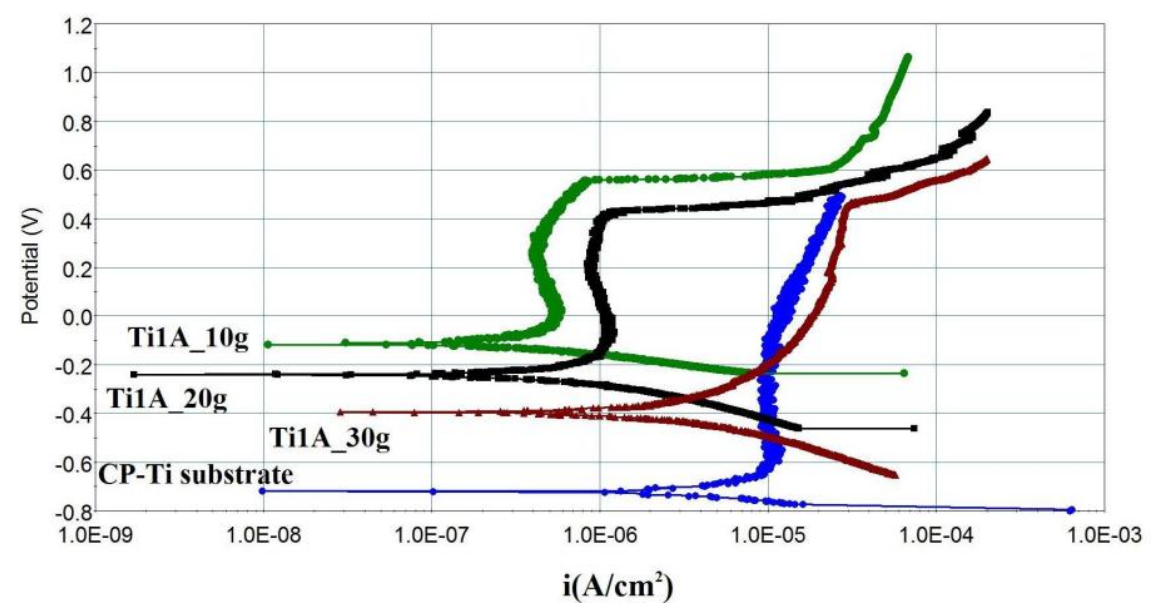

Fig. 15. Potentiodynamic polarization curves of the tested samples: CP-Ti substrate, Ti1A_10g, Ti1A_20g and Ti1A_30g samples.

\section{Conclusions}

Deposited PEO layers on CP-Ti in acidic electrolyte solution $\left(20 \mathrm{~g} / \mathrm{L} \mathrm{NaH} 2 \mathrm{PO}_{4} \cdot 2 \mathrm{H}_{2} \mathrm{O}\right)$ operated both in potentiostatic (first set of samples) and galvanostatic (second set of samples) modes contain polycrystalline rutile and anatase $\mathrm{TiO}_{2}$ phases and a small amount of amorphous phases.

The relative mass concentration of rutile $\mathrm{TiO}_{2}$ in the coatings obtained under potentiostatic regime does not differ significantly from those obtained in galvanostatic mode.

By using a potentiostatic mode, the oxide surface coatings yield much better mechanical properties (390-450 $\mathrm{HV}_{300}$ microhardness and $\mathrm{L}_{\mathrm{c} 2}=11-19 \mathrm{~N} ; \mathrm{L}_{\mathrm{c} 3}=19-38 \mathrm{~N}$ scratch resistance) as compared to the galvanostatic process $\left(300-270 \mathrm{HV}_{300} ; \mathrm{L}_{\mathrm{c} 2}=4-7 \mathrm{~N} ; \mathrm{L}_{\mathrm{c} 3}=8-11 \mathrm{~N}\right)$.

The PEO layer thickness is between 2 and $10 \mu \mathrm{m}$ and the corrosion resistance in Ringer's physiological solution of potentiostatically $\left(60-280 \mathrm{nA} / \mathrm{cm}^{2}\right)$ and galvanostatically $(20-270$ $\mathrm{nA} / \mathrm{cm}^{2}$ ) grown coatings is of $1-2$ orders of magnitude higher when compared to CP-Ti (1800 $\left.\mathrm{nA} / \mathrm{cm}^{2}\right)$. 
From the microstructure point of view, the observed spherical nanograins were composed of rutile $(48-98 \mathrm{~nm})$ and anatase $(45-64 \mathrm{~nm}) \mathrm{TiO}_{2}$ particles, the anatase to rutile phase transformation mechanism being restricted by the inhibiting influence of the chemisorbed phosphate ions on the surface along with the critical particle size effect responsible for anatase particle growth suppression as a result of lower surface free energy of anatase compared to rutile. Thus, a decreasing relative mass concentration of rutile $\mathrm{TiO}_{2}$, from $27.3 \%$ to $17.5 \%$ with the increase of $\mathrm{NaH}_{2} \mathrm{PO}_{4} \cdot 2 \mathrm{H}_{2} \mathrm{O}$ electrolyte concentration, from $10 \mathrm{~g} / \mathrm{L}$ to $30 \mathrm{~g} / \mathrm{L}$ (third set of samples), confirms the above inhibition mechanism of anatase-rutile phase transformation as a consequence of decreasing surface energy of anatase $\mathrm{TiO}_{2}$ crystallites by increasing the number of adsorbed phosphorus ions $\left(\mathrm{H}_{2} \mathrm{PO}_{4}^{-}, \mathrm{PO}_{4}{ }^{3-}\right)$.

\section{References}

[1] D. M. Brunette et al., Titanium in Medicine: materials science, surface science, engineering, biological responses and medical applications, Springer Berlin, 2001

[2] Christoph Leyens, Manfred Peters, Titanium and Titanium Alloys: fundamentals and applications, WileyVCH, Köln (2003)

[3] C. N. Elias et al., JOM 60 (2008) 46-49

[4] Dongdong Gu et al., Acta Mater. 60 (2012) 3849-3860

[5] S. Nemat-Nasser et al., Acta Mater. 47 (1999) 3705-3720

[6] M. A. Khan et al., Biomaterials 17 (1996) 2117-2126

[7] X. D. Zhang et al., Appl. Surf. Sci. 257 (2011) 5899-5902

[8] Seiji Ban et al., Dent. Mater. 22 (2006) 1115-1120

[9] Y. Z. Yang et al., J. Biomed. Mater. Res. 52 (2000) 333-337

[10] R. H. U. Khan et al., Surf. Eng. 30 (2014) 102-108 
[11] M. Shokouhfar et al., Appl. Surf. Sci. 258 (2012) 2416-2423

[12] Satendra Kumar et al., Mater. Sci. Eng. C 29 (2009) 1942-1949

[13] Y. Xia et al., Appl. Surf. Sci. 289 (2014) 306-315

[14] L. Jing et al., Appl. Surf. Sci. 258 (2012) 3340-3349

[15] Jose Criado and Concha Real, J. Chem. Soc. Farad. T1 79 (1983) 2765-2771

[16] Masoud Roknian et al., J. Mater. Eng. Perform. 27 (2018) 1343-1351

[17] Po-Jen Chu et al., Ceram. Eng. Sci. Proc. (2014) 117-127

[18] R.H.U. Khan, et al., Philos. Mag. 88 (2008) 795-807

[19] T. Hanawa, Mater. Sci. Eng. A267 (1999) 260-266

[20] Kazuhisa Shimazaki and Vert Mooney, J. Orthop. Res. 3 (1985) 301-310

[21] V. Malinovschi et al., Surf. Coat. Tech. 253 (2014) 194-198

[22] R.A. Spurr and H. Myers, Anal. Chem. 29 (1957) 760-762

[23] Paul Scherrer, Göttinger Nachrichten Gesell. 2 (1918) 98-100

[24] F. Moulder, W. F. Stickle, P. E. Sobol, and K. D. Bomben, Handbook of X-Ray Photoelectron Spectroscopy (ULVAC-PHI, Inc., Chigasaki, Japan, 1995

[25] D. Krupa et al., Biomaterials 23 (2002) 3329-3340

[26] Wei Cui et al., Appl. Catal. B 164 (2015) 144-150

[27] T. Hanawa and M. Ota, Appl. Surf. Sci. 55 (1992) 269-276

[28] D.-J. Won et al., Appl. Phys. A 73 (2001) 595-600

[29] Long-Hao Li et al., Biomaterials 25, (2004), 2867-2875

[30] R. O. Hussein et al., J. Phys. D: Appl. Phys. 43 (2010) 105203

[31] A. L. Yerokhin et al., Surf. Coat. Tech. 122 (1999) 73-93

[32] B. L. Jiang and Y. M. Wang, Plasma electrolytic oxidation treatment of aluminium and titanium alloys. Surface Engineering of Light Alloys. Aluminium, Magnesium and Titanium Alloys, Woodhead Publishing Series in Metals and Surface Engineering (2010) 110-154 
[33] Po-Jen Chu et al., Thin Solid Films 519 (2010) 1723-1728

[34] E. Matykina et al., Acta Biomater. 5 (2009) 1356-1366

[35] Wojciech Simka et al., Electrochim. Acta 54 (2009) 6983-6988

[36] J. I. Langford and A. J. C. Wilson, J. Appl. Cryst. 11 (1978) 102-113

[37] A. L. Yerokhin et al., Surf. Coat. Tech. 130 (2000) 195-206

[38] K. C. Tekin et al., Surf. Eng. 32 (2016) 435-442

[39] S. Gowtham et al., Surf. Coat. Tech. 301 (2016) 63-73 